\title{
MODELLING HEAT GENERATION DURING FRICTION AND VISCOPLASTIC DEFORMATION BASED ON THE EXAMPLE OF THE YENISEI SHEAR ZONE (EASTERN SIBERIA)
}

\section{O.P. Polyansky $₫$, A.V. Babichev $₫$, A.N. Semenov ${ }^{\circledR}$, V.V. Reverdatto}

Sobolev Institute of Geology and Mineralogy, Siberian Branch of the Russian Academy of Sciences, 3 Academician Koptyug Ave, Novosibirsk 630090, Russia

ABSTRACT. Deviations of the PT parameters from the background values, corresponding to the lithostatic pressure and the standard geotherm characteristic of the neighboring crustal blocks of the Yenisei Ridge, were recorded by geothermobarometry in the zones of dislocation metamorphism of the Yenisei regional shear zone (Eastern Siberia). To explain the reason for large deviations from metamorphic conditions for shear and collision, we worked out 3D and 2D thermomechanical numerical models. The paper presents two- and three-dimensional models of dissipative heating during friction and visco-plastic deformations. The modelling results are compared with geological observations on the metamorphic grade and the scale of deformations of the Yenisei regional shear zone. A detailed consideration is being given to the ratio of heat released during friction at the contact of shear fault blocks, or during viscous deformations of the rheologically layered zone of tectonic flow and blastomylonitization. Estimates of the magnitude of dissipative heating are obtained for typical parameters of shear zones. The model of viscous deformation of a shear zone of finite width, taking into account the rheological layering of the crust, predicts dissipative heating by $200-310{ }^{\circ} \mathrm{C}$ at strain rates of $2-4 \mathrm{~cm} / \mathrm{year}$. The model of obduction of the tectonic plate with a thrusting velocity of $5 \mathrm{~cm} /$ year yields estimates of frictional heating of rocks at the contact of blocks no higher than $130-190{ }^{\circ} \mathrm{C}$. The characteristic time period of the stationary dissipative regime formation is 6-8 million years. Dissipative heating could be a heat source for the metamorphic complexes of the Yenisei regional shear zone, though melting conditions of metapelite were not attained.

KEYWORDS: Yenisei Range; Isakovka block; heat transfer; numerical modelling; viscosity; heat dissipation; shear zone

FUNDING: This work was supported by RSF (project 21-77-20018).

\section{RESEARCH ARTICLE}

FOR CITATION: Polyansky O.P., Babichev A.V., Semenov A.N., Reverdatto V.V., 2021. Modelling heat generation during friction and viscoplastic deformation based on the example of the Yenisei shear zone (Eastern Siberia). Geodynamics \& Tectonophysics 12 (4), 909-928. doi:10.5800/GT-2021-12-4-0563 


\title{
МОДЕЛИРОВАНИЕ ТЕПЛОГЕНЕРАЦИИ ПРИ ТРЕНИИ И ВЯЗКОПЛАСТИЧЕСКОЙ ДЕФОРМАЦИИ НА ПРИМЕРЕ ПРИЕНИСЕЙСКОЙ СДВИГОВОЙ ЗОНЫ (ВОСТОЧНАЯ СИБИРЬ)
}

\author{
О.П. Полянский, А.В. Бабичев, А.Н. Семенов, В.В. Ревердатто
}

Институт геологии и минералогии им. В.С. Соболева СО РАН, 630090, Новосибирск, пр-т Академика Коптюга, 3, Россия

АНнотАЦИЯ. В зонах дислокационного неопротерозойского метаморфизма Приенисейской региональной сдвиговой зоны (ПРСЗ) (Восточная Сибирь) геотермобарометрическими методами зафиксированы отклонения PT-параметров от фоновых значений, соответствующих литостатическому давлению и стандартной палеогеотерме, характерной для соседних блоков коры Енисейского кряжа. Для объяснения причин значительных отклонений условий метаморфизма при сдвиге и коллизии нами разработаны 3D и 2D термомеханические численные модели. В работе представлены результаты двух- и трехмерного моделирования диссипативного нагрева при трении и вязкопластических деформациях. Результаты моделирования сравниваются с геологическими данными о степени метаморфизма и масштабе деформаций ПРСЗ. Детально рассматривается вопрос о соотношении величины тепловыделения при трении на контакте блоков сдвиговых разломов либо при вязких деформациях в реологически расслоенной зоне тектонического течения и бластомилонитизации. Получены оценки величины диссипативного нагрева при типичных параметрах сдвиговых зон, а также с учетом наличия расплава. Модель вязкого деформирования сдвиговой зоны конечной ширины в неоднородной по реологии и составу коре предсказывает диссипативный нагрев на 200-310 드 при скорости деформации 2-4 см/год. Модель обдукции тектонической пластины со скоростью надвигания 5 см/год дает оценки нагрева пород при трении на контакте блоков не более $130-190^{\circ} \mathrm{C}$. Характерное время установления стационарного режима диссипативного нагрева в режиме сдвига составляет 6-8 млн лет. Для метаморфических комплексов ПРСЗ диссипативный нагрев мог являться тепловым источником метаморфизма и мигматизации, однако условия формирования крупных гранитных интрузий не достигались.

КЛЮЧЕВЫЕ СЛОВА: Енисейский кряж; Исаковский блок; теплоперенос; численное моделирование; вязкость; диссипация тепла; зона сдвига

ФИНАНСИРОВАНИЕ: Исследование выполнено при поддержке Российского научного фонда (проект № 2177-20018).

\section{1. ВВЕДЕНИЕ}

Эффект тепловыделения за счет диссипативного нагрева при трении и вязких деформациях рассматривается как один из возможных источников тепла при метаморфизме. Процесс преобразования механической работы в тепло характерен для сдвиговых поясов и проявлен в широком спектре условий метаморфизма: от зеленосланцевого до ультраметаморфизма и анатексиса. Количество тепла, выделяемого при деформациях, зависит от реологических и теплопроводящих свойств сдвиговой зоны, скорости и длительности тектонического процесса [Mako, Caddik, 2018]. Оценки роста температуры за счет тепловыделения при деформациях и трении различаются в несколько раз: от первых десятков [Mori et al., 2015] до первых coтен градусов, вплоть до условий частичного плавления [Leloup et al., 1999; Nabelek et al., 2010]. Обычно плавление весьма локально, однако иногда в зонах сдвига предполагается образование значительных объемов кислых расплавов, формирующих граниты.

В немногочисленных исследованиях роли тепловыделения при деформациях и трении в природных системах вопрос об источнике тепла в сдвиговых зонах и коллизионных орогенах часто остается дискуссионным.
Определить величину диссипативного нагрева в природных метаморфических системах удается достаточно редко [Mako, Caddick, 2018]. Примерами геологических объектов, в которых установлен вклад диссипативного тепла, являются Лепонтийский гнейсовый купол [Burg, Gerya, 2005], разлом в метаморфическом поясе Санбагава, Япония [Mori et al., 2015], мусковит-биотитовые лейкограниты Армориканской сдвиговой зоны [Strong, Hanmer, 1981], лейкограниты Главного Гималайского надвига [Nabelek et al., 2010], интрузии гранитов и монцонитов в сдвиговой зоне разлома АйлаоШань - Рэд Ривер (Китай - Вьетнам) [Leloup et al., 1999; Izokh et al., 2004]. Оценки температурных аномалий за счет тепла трения при сдвиге составляют $100{ }^{\circ} \mathrm{C}$ (до $\sim 700{ }^{\circ} \mathrm{C}$ ) в зоне вертикального разлома при 5-6 кбар [Strong, Hanmer, 1981] и достигают условий плавления гранита (700-800 $\left.{ }^{\circ} \mathrm{C}\right)$ на глубине 20-40 км при пологом надвиге [Nabelek et al., 2010]. Установлено, что выплавление лейкогранитов в Гималайском коллизионном орогене возможно за счет тепла трения при непрерывных деформациях со скоростью 3 см/год в течение 8 млн лет [Nabelek et al., 2010]. Тепло трения и вязких деформаций имеет ограниченный термомеханический эффект и, в частности, не может являться 
$90^{\circ}$

$96^{\circ}$ в.д.

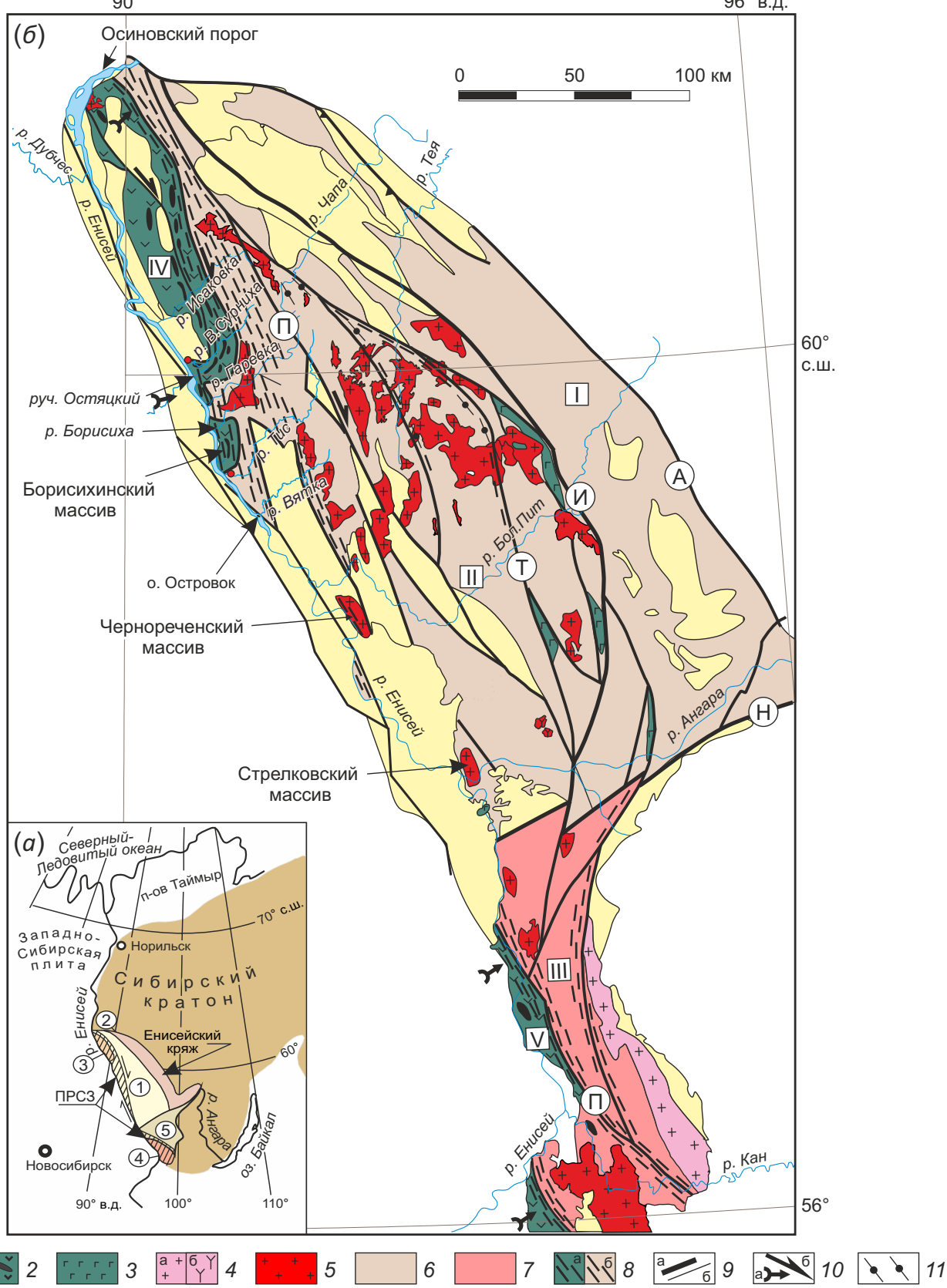

Рис. 1. Карта основных структур Енисейского кряжа по [Vernikovsky et al., 2003; Likhanov et al., 2021].

$(a)$ - положение тектонических блоков на западной окраине Сибирского кратона; (б) - строение Приенисейской региональной сдвиговой зоны и положение бластомилонитовых комплексов. Блоки (цифры в квадратах): I - Восточно-Ангарский, II Центрально-Ангарский, III-IV - островодужные блоки: III - Ангаро-Канский, IV - Исаковский; V - Предивинский. 1 - чехол $\left(\mathrm{NP}_{3}-\mathrm{PH}\right) ; 2$ - офиолитовые и островодужные комплексы с плагиогранитами (NP); 3 - основные вулканиты (MP-NP); 4 - неопротерозойские гранитоиды (NP); 5 - палеопротерозойские гранитоиды (PP); 6-7 - метаморфические комплексы: 6 - от фации зеленых сланцев до амфиболитовой (NA-NP $\left.{ }_{1-2}\right), 7$ - гранулит-гнейсовые (PP); 8 - бластомилониты зон: а - шовной, б - фронтальной; 9 - разломы и геологические границы: а - региональные разломы, надвиги (границы блоков): И - Ишимбинский, Т - Татарский, А - Анкиновский, П - Приенисейский, Н - Ангарский, б - геологические границы (ЕК); 10 - направление тектонических движений (NP): а - поддвиги, б - сдвиги; 11 - ставролит-гранат-кианитовые тектониты.

Fig. 1. Map of the main structures of the Yenisei Ridge after [Vernikovsky et al., 2003; Likhanov et al., 2021].

(a) - position of tectonic blocks on the western margin of the Siberian craton; (6) - the structure of the Yenisei regional shear zone and the position of blastomylonite complexes. Blocks (figures in squares): I - East Angara, II - Central Angara, III-IV - island arc terranes: III - Angara-Kan, IV - Isakovsky; V - Predivinsky. 1 - cover ( $\left.\mathrm{NP}_{3}-\mathrm{PH}\right) ; 2$ - ophiolite and island arc complexes with plagiogranites (NP); 3 - basic volcanics (MP-NP); 4 - Neoproterozoic granitoids (NP); 5 - Paleoproterozoic granitoids (PP); 6-7 - metamorphic complexes: 6 - from greenschist to amphibolite facies (NA-NP ${ }_{1-2}$ ), 7 - granulite-gneiss (PP); 8 - blastomylonitic zones: a - suture, 6 - frontal; 9 - faults and geological boundaries: a - regional faults, thrusts (block boundaries): И - Ishimbinsky, Т - Tatarsky, A - Ankinovsky, $\Pi$-Yenisei, H - Angarsky, 6 - geological boundaries (EK); 10 - direction of tectonic movements (NP): a - underthrusts, 6 - strike-slips; 11 - staurolite-garnet-kyanite tectonites. 
(a)

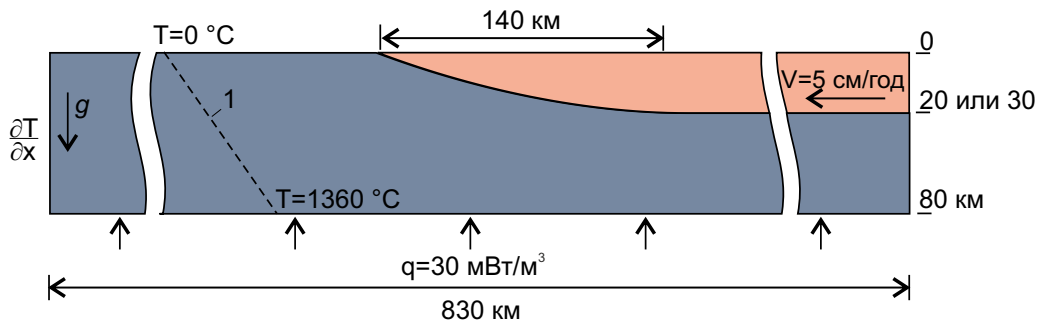

(б)

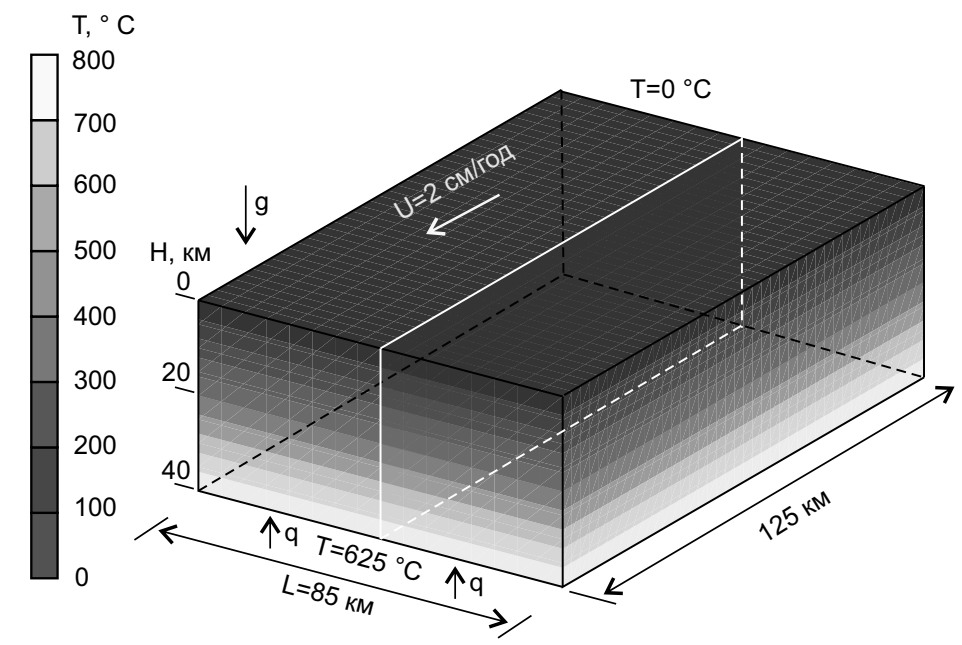

$(8)$

Расчетная область (зона сдвиговых деформаций)

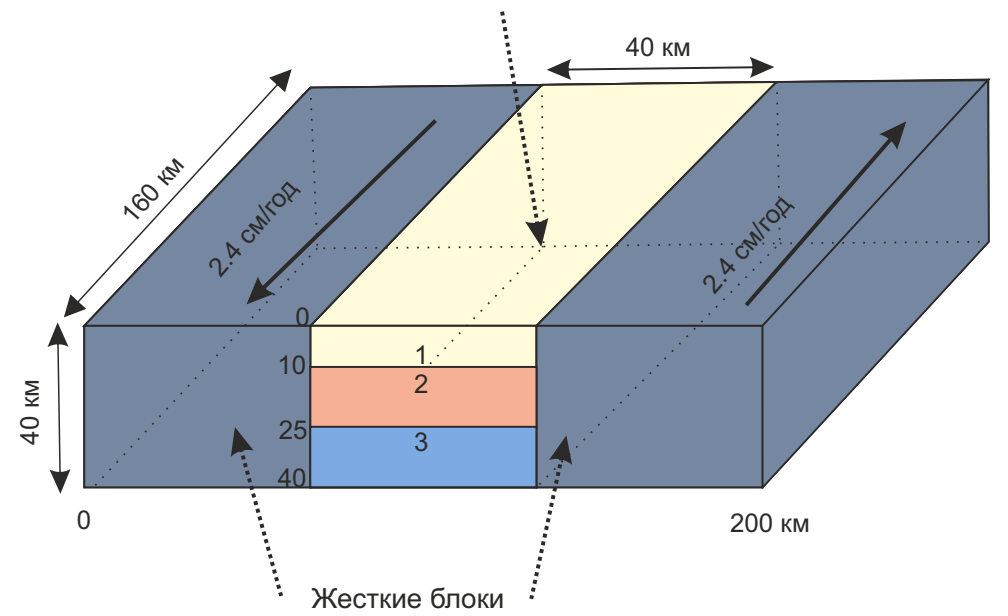

Рис. 2. Три модели теплогенерации в коре за счет трения и вязкой диссипации в ходе эволюции Приенисейской региональной сдвиговой зоны. Граничные условия и характеристики моделей см. в тексте.

(a) - 2D модель фрикционного тепловыделения при надвиге тектонической пластины мощностью 20 или 30 км по листрическому разлому. Показаны температурные граничные условия. Кривая 1 показывает начальное распределение температуры в области; (б) - 3D модель тепловыделения при трении при движении двух блоков относительно вертикального разлома. Показаны величина скорости сдвига и направление, тоном показано начальное распределение температуры; (8) - 3D модель термического режима вязко-деформируемой сдвиговой зоны. Стрелки означают перемещения обрамляющих жестких блоков с заданной скоростью. Расчетная область (центральная часть модели) - трехслойная вязко-деформируемая кора метаосадочного (1), диоритового (2) и гранулитового (3) состава с различными реологическими свойствами, указанными в табл. 1.

Fig. 2. Three types of models of heat generation in the crust due to friction and viscous dissipation during the evolution of the Yenisei regional shear zone. For the boundary conditions and characteristics of the models see the text.

(a) - 2D model of frictional heating during the thrust of a 20-30 km thick tectonic plate along the listric fault. Thermal boundary conditions are indicated. Curve 1 shows the initial temperature distribution in the region; (6) - 3D model of frictional heating when two blocks move relative to a vertical fault. The dimensions of the computational domain, the magnitude of the shear strain rate and the direction are indicated, the initial temperature distribution is shown in tone; $(8)-3 \mathrm{D}$ model of the thermal regime of the viscous-deformable shear zone. The arrows indicate the movement of the enclosing rigid blocks at a given velocity. The computational domain (the central part of the model) is a three-layer viscous-deformable crust of metasedimentary (1), diorite (2), and granulite (3) composition with different rheological properties indicated in Table 1. 
причиной ультравысокотемпературного метаморфизма [Kelsey, Hand, 2015].

Одним из примеров интенсивно деформированных пород с перекристаллизацией субстрата, образованием бластомилонитов, проявлением процессов анатексиса и гранитоидного магматизма можно считать фрагмент Саяно-Енисейского глубинного разлома, протягивающегося вдоль юго-западного обрамления Сибирского кратона (рис. 1, а). Саяно-Енисейский глубинный разлом рассматривается в работе [Rosen et al., 1994] как единая система Саянской, Дербинской зон сдвига и Приенисейского структурного шва, включающего множество разноранговых разломов, главные из которых Исаковский, Ишимбинский, Татарский, Приенисейский и др. В заангарской части Енисейского кряжа была выделена [Kozlov et al., 2012] Приенисейская региональная сдвиговая зона (ПРСЗ), которая прослеживается не менее чем на 200 км вдоль его западного обрамления при ширине 30-50 км. Ее структура представляет собой сочленение континентальной гнейсо-амфиболитовой тектонической пластины (Гаревский комплекс) и палеоокеанического метабазит-ультрабазитового Исаковского блока, разделенных разломами сдвиго-взбросового и надвигового типа. Сдвиговые зоны проявлены структурами преимущественно правосдвиговой кинематики и бластомилонитами с преобладающими элементами ламинарного течения.

Характерной особенностью является проявление приразломного катаклаза, меланжирования и дислокационного метаморфизма. Более интенсивно деформированные тектониты, как правило, приурочены к приразломным зонам или полосам локализации деформаций. Множественные сдвиги в приразломных полях пластичных деформаций сопровождаются формированием мощных зон бластомилонитов (рис. 1).

В геодинамической эволюции Приенисейской палеосубдукционной зоны выделяется субдукционно-островодужный этап в период 730-700 млн лет [Likhanov et al., 2021], формирование офиолитовых и островодужных комплексов Исаковского блока 700-630 млн лет [Vernikovsky et al., 2003] и аккреционно-коллизионный этап - 640-600 млн лет. Возраст образованных в зоне палеосубдукции продуктов глаукофансланцевого метаморфизма отвечает интервалу времени 640-620 млн лет. На постсубдукционном этапе при эксгумации глаукофансодержащие породы подвергались интенсивным деформациям в шовной зоне с возрастом около 600 млн лет, маркирующим время завершения аккреции Исаковского блока к западной окраине Сибирского кратона [Kozlov et al., 2020].

Методом геотермобарометрии установлены значимые различия параметров метаморфизма для различных генераций метабазитов [Likhanov et al., 2018]. PTпараметры допиковой ассоциации, вычисленные по составам фаз-включений и контактирующего с ними граната, оцениваются в 8-9 кбар/385-440 ㄷ․ Кульминационные термодинамические условия в тектонитах шовной зоны определены как 10-15 кбар/550-620 으, что свидетельствует о наложении более высокотемпературных и высокобарических минеральных ассоциаций на ранние парагенезисы. Формирование апоглаукофановых бластомилонитов в ходе наложенных интенсивных сдвиговых деформаций происходило с максимальным повышением давления на 3-5 кбар с одновременным ростом температуры на $180-240{ }^{\circ} \mathrm{C}$. Авторы [Likhanov et al., 2021] предполагают, что тектонические касательные напряжения могли быть причиной генерации всестороннего давления, превышающего литостатическое. Тогда изменения РТ-параметров происходят не в соответствии с установившимся геотермическим градиентом, а вызваны тектоническими факторами. В рамках этого механизма возникает вопрос о природе источника тепла, альтернативного нагреву при погружении или за счет магматического тепла. Так как высокотемпературный метаморфизм и формирование тектонитов ПРСЗ происходят совместно [Likhanov et al., 2021], то диссипативный нагрев может рассматриваться как потенциальный источник тепла.

Для оценки эффекта тепловыделения за счет трения в разломах в условиях сдвига и коллизии нами разработаны 3D и 2D термомеханические численные модели, описывающие взаимосвязь триады: реология вещества - деформация - диссипативный нагрев. Данная методика может быть применена к множеству подобных природных структур, она открыта для добавления специфических граничных и начальных условий, учета дополнительных физико-химических факторов, усложнения геометрических моделей в соответствии с будущим моделируемым объектом. Цель работы состоит в определении величины нагрева и размеров температурных аномалий для двух разных механизмов: 1) теплогенерации на контакте блоков, разделенных одиночным разломом сдвигового или надвигового типа (модели показаны на рис. 2, а, б); 2) теплогенерации в вязко-деформируемой сдвиговой области коры, заключенной между перемещающимися жесткими блоками (модель показана на рис. 2, в). Важным фактором эффективности тепловыделения при деформациях является наличие расплава в деформируемых породах. Влияние плавления на реологию пород и эффект присутствия частичного расплава изучены в рамках модифицированной модели сдвига, показанной на рис. 2, в.

\section{2. МОДЕЛИРОВАНИЕ ТЕПЛОГЕНЕРАЦИИ ПРИ ТРЕНИИ НА КОНТАКТЕ БЛОКОВ ПРИ НАДВИГЕ И СДВИГЕ}

Были рассмотрены две ситуации: тепловыделение при трении на дискретных разломах сдвигового и надвигового типа.

Геодинамическая модель надвига тектонической пластины (аллохтон) по листрическому разлому, описывающая обдукцию исаковских офиолитов на континентальную окраину (рис. 2, а), рассматривалась в двумерной постановке. В этой модели предполагается, что граница надвига разделяет Исаковский блок 
(см. рис. 1, б, блок IV) и палеоконтинентальные блоки (I и II).

Задача выделения тепла трения при сдвиге двух блоков, контактирующих по вертикальной плоскости разлома, решалась в трехмерной постановке (рис. 2, б). В модели одиночного разлома вертикальная поверхность контакта соответствует границе между Центрально-Ангарским (см. рис. 1, б, блок II) и Исаковским блоком высокобарических бластомилонитов (блок IV).

Математическое моделирование контактового взаимодействия блоков с учетом фрикционной теплогенерации проводилось в рамках механики деформируемого твердого тела (МДТТ). Решались уравнения механического равновесия и уравнения теплопроводности в связной постановке с использованием реологических соотношений для упругопластического материала блоков коры. Задача МДТТ решалась без учета инерционных членов в уравнениях движения как квазистатическая. Дискретизация уравнений МДТТ проводилась методом конечных элементов [Korobeynikov, 2000]. Численное моделирование выполнялось с использованием пакета программ MSC.Marc в двумерной и трехмерной постановке, с учетом нелинейности деформирования, контактного взаимодействия и свойств среды. Подробные формулировки уравнений, описание численного метода, а также реологические параметры моделей приведены в работах [Korobeynikov, 2000; Korobeynikov et al., 2009, 2011; Polyansky et al., 2014] и здесь не повторяются. Использование подхода МДТТ как альтернативного гидродинамическому, основанному на уравнениях Навье-Стокса, обусловлено хрупкоупругопластической реологией материала коры.

2D задача надвига решалась в приближении плоских деформаций (рис. 2, а). В качестве закона, описывающего поведение вещества, была использована модель упругопластического тела с функцией текучести Хубера Мизеса [Korobeynikov et al., 2011]:

$$
\begin{aligned}
& F^{h}(\sigma) \equiv\left(\frac { 1 } { 6 } \left(\left(\sigma_{11}-\sigma_{22}\right)^{2}+\left(\sigma_{22}-\sigma_{33}\right)^{2}+\right.\right. \\
& \left.\left.+\left(\sigma_{33}-\sigma_{11}\right)^{2}\right)+\sigma_{12}^{2}+\sigma_{23}^{2}+\sigma_{31}^{2}\right)^{1 / 2}-\frac{\sigma_{y}}{\sqrt{3}},
\end{aligned}
$$

где $\sigma_{i j}$ - компоненты тензора напряжений $(i, j=1,2,3)$, $\sigma_{y}$ - предел текучести.

B 3D задаче сдвига двух блоков вдоль вертикальной плоскости (рис. 2, б) использована модель упругопластического материала с конической функцией текучести Друкера - Прагера [Korobeynikov et al., 2011] следующего вида:

$$
\begin{gathered}
F^{h}(\sigma) \equiv \alpha\left(\sigma_{11}+\sigma_{22}+\sigma_{33}\right)+\left(\frac { 1 } { 6 } \left(\left(\sigma_{11}-\sigma_{22}\right)^{2}+\right.\right. \\
\left.\left.+\left(\sigma_{22}-\sigma_{33}\right)^{2}+\left(\sigma_{33}-\sigma_{11}\right)^{2}\right)+\sigma_{12}^{2}+\sigma_{23}^{2}+\sigma_{31}^{2}\right)^{1 / 2}-\frac{\sigma_{y}}{\sqrt{3}} .
\end{gathered}
$$

Более подробно поведение материала в рамках моделей пластичности Друкера - Прагера и Хубера - Мизеса рассмотрено в [Korobeynikov et al., 2011]. В модели были приняты значения параметров функции текучести: $\alpha=0.123$ - аналог коэффициента трения, $\sigma_{y}=14.2 \mathrm{MПа} \mathrm{-}$ аналог коэффициента сцепления в законе Кулона-Мора, что соответствует значениям для пород верхней коры [Korobeynikov et al., 2011]. Физические свойства материалов блоков приведены в табл. 1.

В обоих вариантах математическая модель учитывает контактное взаимодействие блоков, их деформирование и разогрев при трении на бортах разлома в коре. Условия на поверхности разлома удовлетворяют

\begin{tabular}{|c|c|c|c|c|c|c|c|c|}
\hline \multirow{2}{*}{$\begin{array}{l}\text { Материал коры } \\
\text { Блоки в модели сдвига } \\
\text { и автохтон в модели } \\
\text { надвига }\end{array}$} & \multirow{2}{*}{$\begin{array}{c}\rho, \\
\kappa \Gamma / \mathrm{M}^{3} \\
\\
3000\end{array}$} & \multirow{2}{*}{$\begin{array}{l}\text { Толщина, } \\
\text { км } \\
\\
40\end{array}$} & \multirow{2}{*}{ 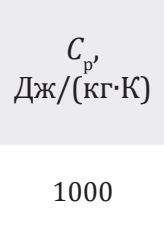 } & \multirow{2}{*}{$\begin{array}{c}k, \\
\mathrm{BT} /(\mathrm{M} \cdot \mathrm{K}) \\
\\
2\end{array}$} & \multicolumn{4}{|c|}{$\begin{array}{c}\text { Механические свойства блоков } \\
\text { Модуль Юнга } E \text { (ГПа), коэффициент Пуассона, } \\
\text { предел текучести (МПа), угол трения }\end{array}$} \\
\hline & & & & & & 100,0 & $1.2,0.123$ & \\
\hline Аллохтон (метабазиты) & 2800 & 20,30 & 1250 & 2 & & & , 50,- & \\
\hline \multicolumn{5}{|c|}{ Механизм теплогенерации при вязких деформациях } & $\begin{array}{c}E, \\
\text { КДж/мол }\end{array}$ & $n$ & $\begin{array}{c}A, \\
\prod^{-n} \cdot c^{-1}\end{array}$ & $\begin{array}{c}v, \\
\Pi a \cdot c\end{array}$ \\
\hline 1 - влажный кварцит [1] & 2600 & 10 & 1250 & 2.5 & & & & $10^{21}$ \\
\hline 2 - Qtz-диорит [2] & 2650 & 15 & 1250 & 2.5 & 212 & 2.4 & $3.01 \cdot 10^{-16}$ & \\
\hline $\begin{array}{l}3 \text { - гранулитовый (сухой } \\
\text { ортопироксенит [3]) }\end{array}$ & 2750 & 15 & 1250 & 2.5 & 293 & 2.4 & $1.26 \cdot 10^{-15}$ & \\
\hline
\end{tabular}

Таблица 1. Физические свойства материалов, принятые в моделях

Table 1. Physical properties of materials used in models

Механизм теплогенерации при трении в разломах

Примечание. [1] - [Strehlau, Meissner, 1982]; [2] - [Hansen, Carter, 1982]; [3] - [Raleigh et al., 1971]. Для жестких блоков приняты значения: плотность $\rho=2700$ кг $/ \mathrm{m}^{3}$, теплоемкость $C_{\mathrm{p}}=1250$ Дж/(кг·К) и теплопроводность $k=2.5 \mathrm{Bт} /(\mathrm{M} \cdot К)$.

Note. [1] - [Strehlau, Meissner, 1982]; [2] - [Hansen, Carter, 1982]; [3] - [Raleigh et al., 1971]. Rigid blocks are assigned density $\rho=2700 \mathrm{~kg} / \mathrm{m}^{3}$, heat capacity $C_{\mathrm{p}}=1250 \mathrm{~J} /(\mathrm{kg} \cdot \mathrm{K})$ and heat conductivity $k=2.5 \mathrm{~W} /(\mathrm{m} \cdot \mathrm{K})$. 
закону трения Кулона в режиме stick-slip (прерывистого движения): $\sigma_{t}<\mu \sigma_{n}$ (прилипание), $\sigma_{t}=-\mu \sigma_{n} \boldsymbol{t}$ (скольжение), где $\sigma_{t^{\prime}} \sigma_{n^{\prime}} \mu, \boldsymbol{t}$ - касательное и нормальное напряжение, коэффициент трения, касательный вектор к поверхности разлома в направлении скольжения.

Диссипация энергии при трении обусловлена переходом механической работы в тепло и выражается формулой $q=\gamma \mu \sigma_{n} V$, где $q$ - тепловой поток через единичную поверхность, $V$ - относительная скорость блоков, $\gamma$ - эмпирический параметр, определяющий долю механической энергии, которая преобразуется в тепло. По экспериментальным данным [Lockner, Okubo, 1983], тепло трения скольжения при деформировании сухих гранитных материалов составляет 94 \% общей затраченной энергии на деформацию. В модели не учитываются неоднородности микроуровня: зерна и включения, наличие флюида, шероховатость плоскости бортов разлома. Все эти факторы задаются как средние величины и учитываются посредством выбора коэффициента трения.

Для большинства пород, изученных в лабораторных условиях, коэффициент трения близок к $\mu=0.85$ [Byerlee, 1978]. С другой стороны, оценки сдвиговых напряжений на реальных разломах сдвигового (СанАндреас) и субдукционного типа (Тайвань) говорят о весьма низком трении на разломах: $\mu=0.17-0.25$ для сдвигового разлома Сан-Андреас [Bird, Kong, 1994] и менее 0.1 для субдукционного [Barr, Dahlen, 1989]. Высокие коэффициенты трения соответствуют «сухим» контактам, пониженные - условиям присутствия флюида. В работе варьировались коэффициенты трения закона Кулона между блоками коры в диапазоне 0.300.65 , в задаче о надвиге он принят 0.3. Данный диапазон характерен для условий наличия флюида в зоне разлома, тем самым в модели учитывается влияние флюида на трение.

Геометрия области и граничные условия в 2D модели надвига представлены на рис. 2, а. Блок аллохтона двигается в горизонтальном направлении со скоростью $V=5$ см/год. Нижний блок задается неподвижным, на нижней границе задается тепловой поток $q=30 \mathrm{MBT} / \mathrm{m}^{2}$. Поверхностная эрозия не учитывается.

Геометрия области и граничные условия в 3D модели тепловыделения при трении движущихся блоков относительно вертикального разлома представлены на рис. 2, б. На дневной поверхности задается постоянная температура $\left(0^{\circ} \mathrm{C}\right)$, на нижней границе - постоянный тепловой поток $q=30 \mathrm{mBT} / \mathrm{M}^{2}$. На нижней границе блоков заданы условия свободного скольжения и нулевые вертикальные перемещения, левый блок двигается вдоль плоскости разлома со скоростью $V=2 \mathrm{~cm} /$ год относительно правого, правый блок считается неподвижным. На всех внешних границах блоков отсутствует теплопередача. Начальная температура в коре распределена по линейному закону и показана на рис. 2 , б, серым тоном. В моделях тепло в равной степени передается к одному и другому контактирующему телу. Величина сдвиговых перемещений в 100 км, принятая в модели, соответствует скорости 2-5 см/год при длительности 5-2 млн лет, что согласуется с наблюдениями в современных сдвигово-разломных зонах [Leloup et al., 1999].

\section{3. РЕЗУЛЬТАТЫ МОДЕЛИРОВАНИЯ ТЕМПЕРАТУРНОГО РЕЖИМА ПРИЕНИСЕЙСКОЙ НАДВИГОВОЙ ЗОНЫ}

На рис. 3 представлены результаты по 2D модели надвига в постановке плоских деформаций. На рис. 3, a, б, в, приведена эволюция температурного поля при надвигании плиты Исаковского блока на континентальный неподвижный блок. При перемещении аллохтона относительно автохтона за 10-15 млн лет формируется инвертированное положение изотерм.

Приведено сравнение температур без учета и с учетом тепла трения (рис. 3, г). Температура на горизонтальной глубинной части детачмента (точка II) не меняется в случае отсутствия фрикционного нагрева и повышается на $190{ }^{\circ} \mathrm{C}$ за счет трения при движении плиты Исаковского блока по разлому. Температура на участке т. I - т. II повышается за счет тепла трения и за счет надвигания более нагретых пород.

На рис. 4 представлены результаты расчетов температуры в трехмерной постановке задачи теплогенерации при движении блоков вдоль вертикального одиночного разлома. В окрестности разлома в нижней коре наблюдается локальный разогрев за счет трения за время 5 млн лет при относительном смещении блоков на 100 км (расстояние АБ на рис. 4, а). На рис. 4, б, представлены распределения температуры в основании коры в сечении поперек разлома (в точке Б) для различных значений коэффициента трения в интервале 0.30-0.65. Для модели одиночного разлома фрикционный разогрев в нижней коре зависит от коэффициента трения: при коэффициенте трения $0.30,0.50$, 0.65 температура увеличилась на 100-110, 180-190, $300{ }^{\circ} \mathrm{C}$ соответственно. Трехмерная модель показала, что размер температурной аномалии в основании коры может достигать 30-45 км при вариации коэффициента трения от 0.30 до 0.65 соответственно и сокращается кверху (рис. 4 , б). При достаточно малых значениях коэффициента трения (0.3) в средней и нижней коре при давлении 6-8 и 10 кбар разогрев в зоне разлома составляет 60 и $80^{\circ} \mathrm{C}$ соответственно (рис. 4, в).

\section{3D МОДЕЛЬ ТЕРМИЧЕСКОГО РЕЖИМА ВЯЗКО-ДЕФОРМИРУЕМОЙ СДВИГОВОЙ ЗОНЫ}

В рамках второго подхода рассматривалась зона сдвиговых деформаций фиксированной ширины, заключенная между жесткими движущимися блоками. Модель описывает деформирование континентального блока коры (Гаревский метаморфический комплекс), ограниченного Приенисейским разломом с востока и Исаковским блоком с запада.

Мы использовали трехмерную постановку задачи для определения влияния диссипативного нагревания в вязко-деформируемой сдвиговой зоне. Решается 
(a) Время 1 млн лет
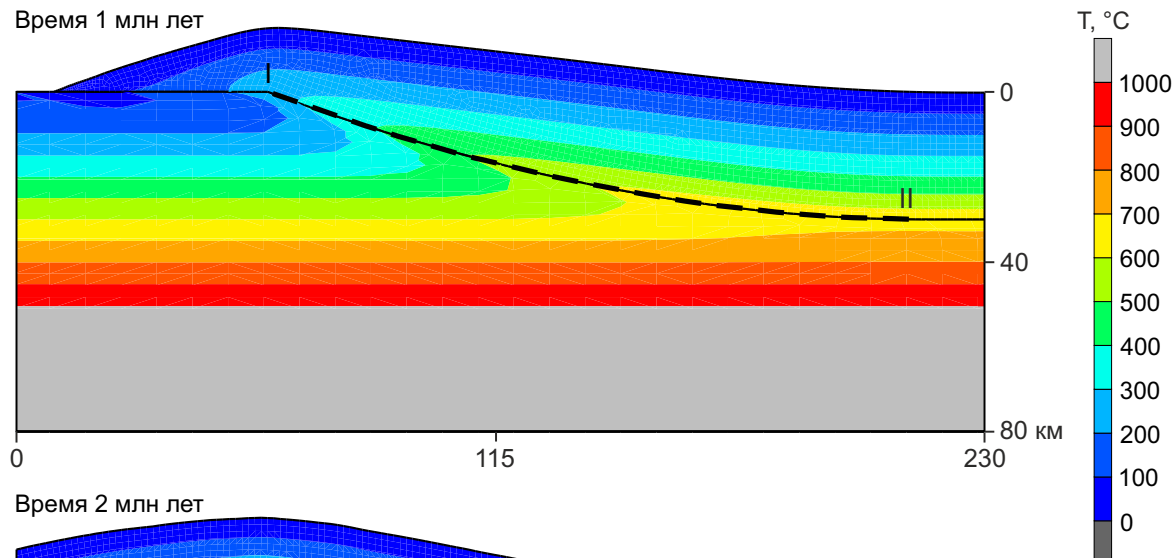

(б) Время 2 млн лет

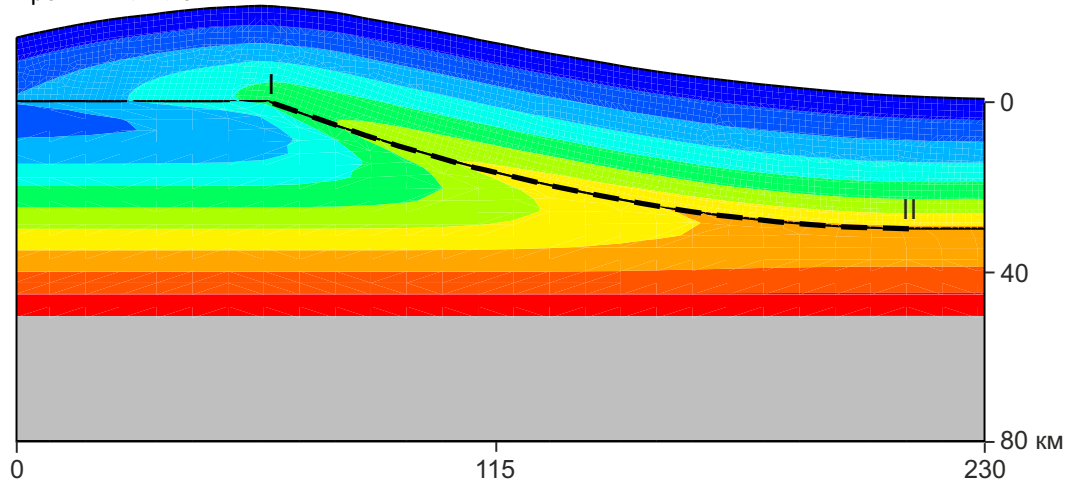

(в) Время 4 млн лет

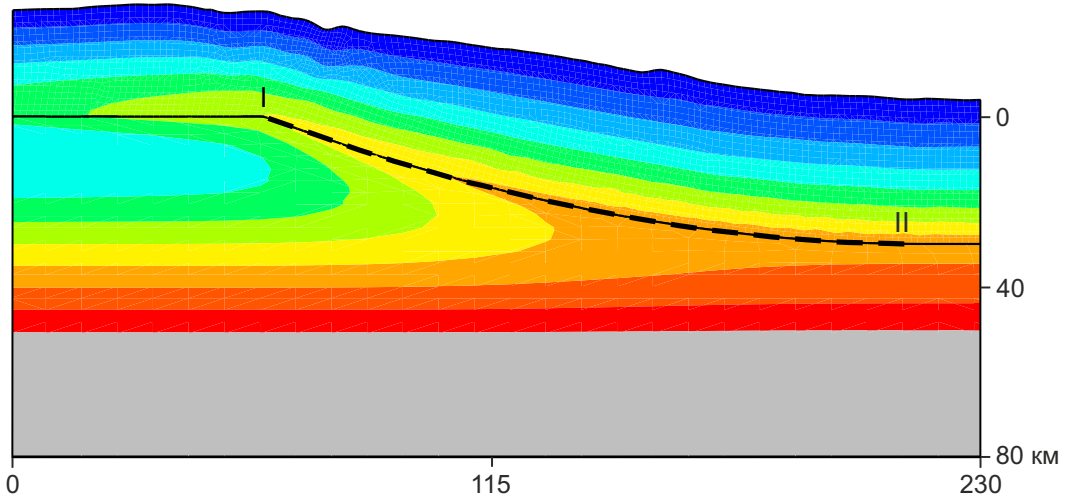

(2)

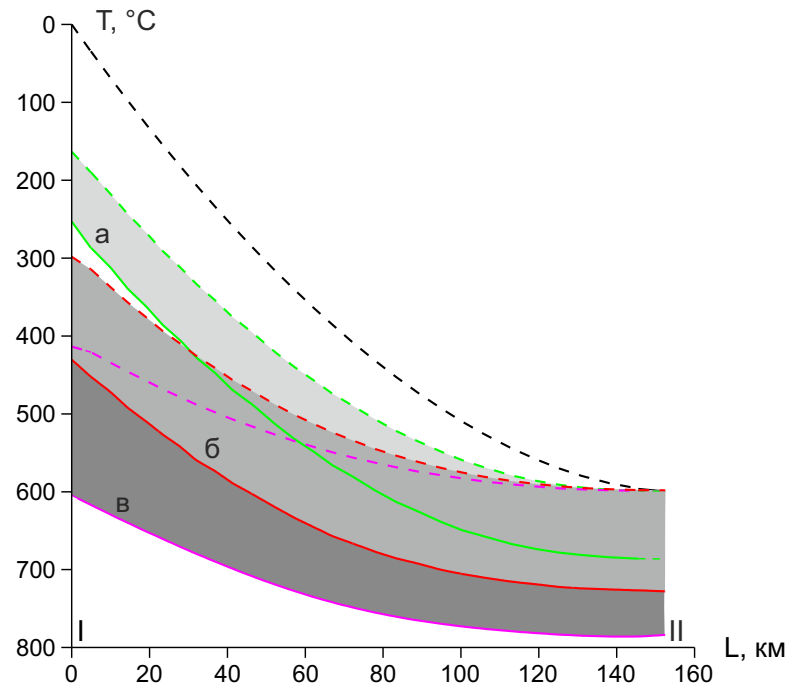

Рис. 3. Результаты моделирования температурного режима при надвиге.

$(a),($ б), (в) - эволюция температуры в зоне надвига с учетом тепловыделения при трении на контакте (I-II) автохтона и аллохтона. Шкала температуры слева, серым показана температура выше $1000{ }^{\circ} \mathrm{C}$. (2) - распределение температуры вдоль сектора детачмента I-II в моменты времени, показанные на фрагментах (a), (б) и ( 8 ). Приведено сравнение температур без учета и с учетом тепла трения (соответственно верхняя и нижняя кривые одного цвета). Начальное (до надвига) распределение 
температуры на контакте блоков соответствует черной пунктирной кривой (распределение температуры, полученное спустя 10 млн лет под действием температурных граничных условий и в отсутствие движения блоков). Температура в точке II постоянна в модели без учета фрикционного нагрева и повышается на $190{ }^{\circ} \mathrm{C}$ за счет тепла трения за 4 млн лет движения по разлому. Температура в т. I повышается за счет надвигания более нагретых пород и тепла трения.

Fig. 3. Results of modeling the temperature regime during thrusting.

(a), (б), ( 8 ) - temperature evolution in the thrust zone taking into account heat generation during friction at the contact (I-II) of autochthon and allochthon. The temperature scale is on the left; the temperature above $1000^{\circ} \mathrm{C}$ shown in gray. (2) - temperature distribution along detachment sector I-II at the time points shown in fragents (a), (б), ( 8$)$. Comparison of temperatures made without and with allowance for frictional heating (respectively, the upper and the lower curves of the same color). The initial (before thrusting) temperature distribution at the contact of the blocks corresponds to the black dashed curve (temperature distribution after 10 Ma under the given temperature boundary conditions and in the absence of block motion). The temperature at point II is constant in case of frictional heating and increases by $190{ }^{\circ} \mathrm{C}$ over a 4 Ma movement along the fault. The temperature in p. I rises due to thrusting of more heated rocks and frictional heat.

(a)

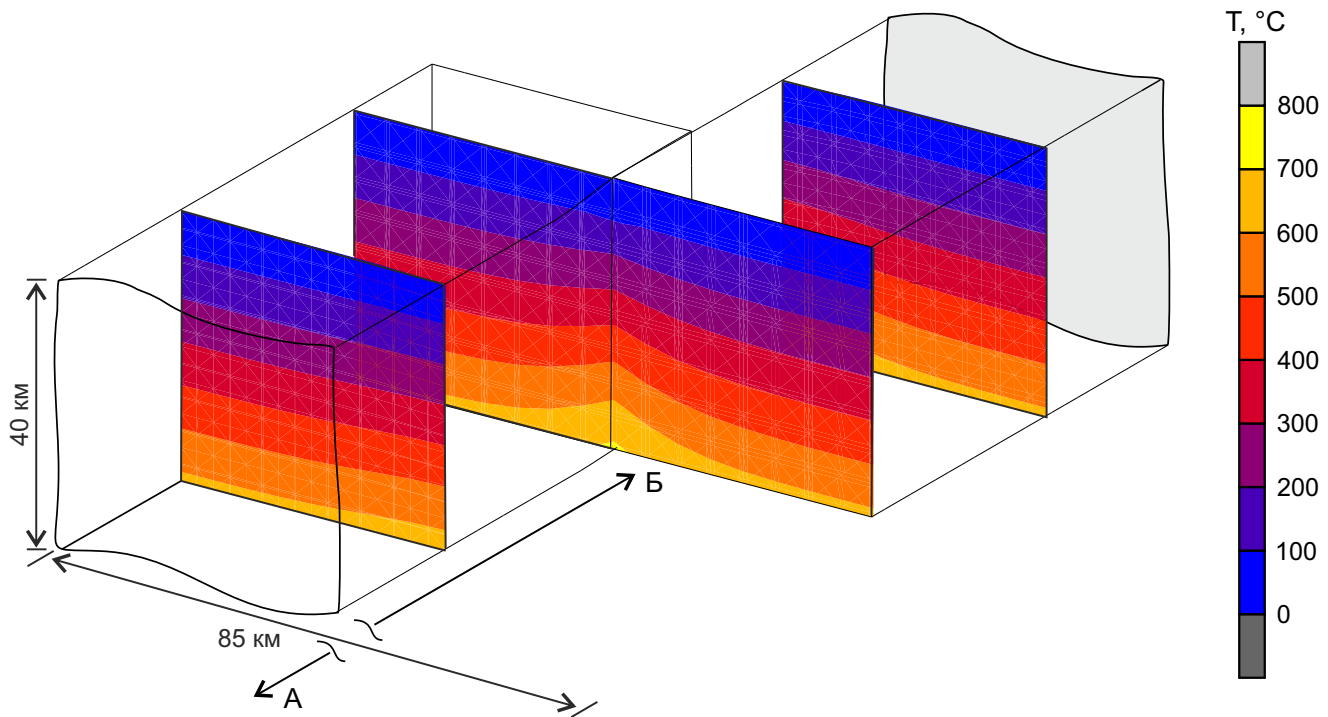

(б)

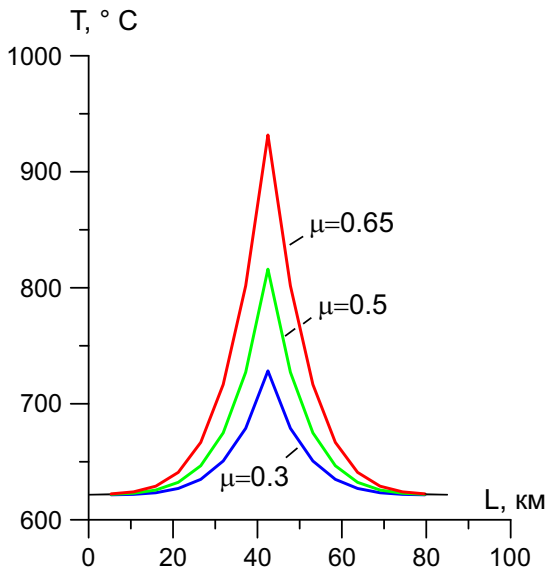

(в)

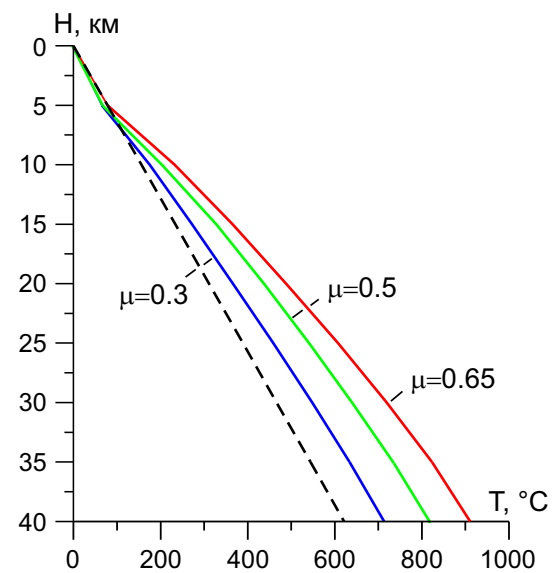

Рис. 4. Результаты 3D численного моделирования теплогенерации при движении вдоль вертикального одиночного разлома. (a) - влияние тепловыделения при трении, показанное в сечениях, перпендикулярных разлому. Цветом показана температура спустя 5 млн лет сдвиговых перемещений при относительном смещении блоков по разлому АБ=100 км; коэффициент трения принят 0.3; (б) - распределения температуры перпендикулярно простиранию разлома в основании коры на глубине 40 км при длительности сдвига 5 млн лет для различных значений коэффициента трения (указаны на рис.); (в) - температура вдоль поверхности разлома при разных значениях коэффициента трения; пунктиром показано начальное распределение температуры.

Fig. 4. Results of 3D numerical modeling heat generation when moving along a vertical single fault.

(a) - influence of heat generation during friction, shown in sections perpendicular to the fault. The color shows the temperature after $5 \mathrm{Ma}$ of shear displacements with a relative shift of blocks along the fault $\mathrm{A} \mathrm{B}=100 \mathrm{~km}$. The friction coefficient is 0.3 ; (б) - temperature distribution perpendicular to the strike of the fault at the base of the crust at a depth of $40 \mathrm{~km}$ with a strike-slip duration of $5 \mathrm{Ma}$ for different values of the friction coefficient (shown in the figure); ( 8 ) - temperature along the fault surface at different values of the coefficient of friction; the dotted line shows the initial temperature distribution. 
система уравнений Навье-Стокса для однофазной среды в приближении сжимаемой жидкости: уравнение неразрывности, уравнение движения и уравнение сохранения энергии. Подробное описание системы уравнений, используемых в модели, приведено в [Semenov, Polyansky, 2017] и здесь не повторяется. Применяется вычислительный пакет ANSYS Fluent [ANSYS..., 2013], в котором реализованы численные алгоритмы для решения задач течения нелинейно-вязкой, температурно-зависимой жидкости. Основное отличие состоит в том, что в уравнении сохранения энергии учитывался член $\overline{\bar{\tau}} \cdot \vec{v}$, отвечающий за вязкостную диссипацию тепла, и уравнение принимает вид:

$$
\frac{\partial}{\partial t}(\rho E)+\nabla \cdot(\vec{v}(\rho E+p))=\nabla \cdot(k \nabla T+(\overline{\bar{\tau}} \cdot \vec{v})),
$$

где $\rho$ - плотность, $E$ - внутренняя энергия, $p$ - статическое давление, $T$ - статическая температура, $k$ - теплопроводность, $\overline{\bar{\tau}}-$ тензор напряжений, $\vec{v}-$ вектор скорости течения.

Для того чтобы определить эффект диссипативного нагрева в уравнении теплового баланса, следует оценить величину безразмерного критерия подобия числа Бринкмана:

$$
B r=\frac{\mu V^{2}}{k \Delta T},
$$

где $\mu$ - вязкость, $V$ - скорость, $k$ - теплопроводность и $\Delta T$ - разность температур. Критерий подобия Бринкмана характеризует соотношение между теплотой, выделяемой за счет вязких деформаций, и теплом, переносимым молекулярной проводимостью. Чем выше его значение, тем медленнее отвод тепла, производимого вязкой диссипацией, и, следовательно, тем больше повышение температуры. При значении этого критерия более 1 эффект вязкой диссипации тепла становится существенным [Aydin, 2005]. Оценка числа Бринкмана в нашем случае: вязкость $\mu>10^{21}$ Па'с, скорость 2 см/год, теплопроводность $k=2.5 \mathrm{BT} /(\mathrm{M} \cdot \mathrm{K})$ и $\Delta T<10^{3}{ }^{\circ} \mathrm{C}$. При указанных характерных параметрах число $\mathrm{Br}>10^{2}$, т.е. вязкостная диссипация тепла превышает теплопередачу за счет теплопроводности и ее влияние следует учитывать [Cordonnier et al., 2012].

На рис. 2, в, представлена геометрия расчетной области коры с граничными условиями. Блоки справа и слева - это твердые тела, в которых решается только уравнение теплопереноса и деформации отсутствуют. Эти блоки рассматриваются как жесткие, движущиеся разнонаправленно тела, обрамляющие сдвиговую зону. Скорость перемещения блоков варьировалась в моделях, результаты приведены для скорости 2 и 4 см/год, таким образом скорость сдвига составляет 4 и 8 см/год. Деформируемая сдвиговая зона представляет собой трехслойную кору метапелит-гранитного, диоритового и гранулитового состава [Веа, 2012]. Строение и состав слоев коры были приняты согласно сейсмическим данным и их интерпретации по [Surkov et al., 1996; Kozlov et al., 2020].
Граничные условия: задаются движения на правой стенке со скоростью 2 см/год и на левой -2 см/год. На верхней границе задана фиксированная температура $27^{\circ} \mathrm{C}$, на нижней границе - тепловой поток 0.022 Вт/ $\mathrm{M}^{2}$. На боковых границах движущихся жестких блоков выполняется условие теплоизолированной стенки (нулевой тепловой поток). Учет вязкой диссипации тепла происходит только в центральной трехслойной области модели. Предварительно был выполнен расчет без учета вязкой диссипации тепла. Это решение использовалось в качестве начального распределения для расчетов с учетом диссипативного нагрева. Начальная температура в коре линейно увеличивается с глубиной от $27^{\circ} \mathrm{C}$ на поверхности до $580{ }^{\circ} \mathrm{C}$ в основании коры.

Расчетная сетка для модельной области структурированная, твердые тела разбиты на тетраэдры с размером грани 250 м, в деформируемой области сетка состоит из тетраэдров с размером грани 100 м.

Физические свойства материалов, характеризующих состав коры, представлены в табл. 1.

Закон вязкого течения (крипа) вещества коры определяется в виде нелинейной зависимости вязкости от температуры и скорости деформации [Burov, 2011; Polyansky et al., 2019a]:

$$
\begin{gathered}
\eta=A^{\frac{-1}{n}}\left[\dot{\varepsilon}_{\mathrm{II}}\right]^{\frac{1-n}{n}} \exp \left(\frac{H}{n R T}\right), \\
\dot{\varepsilon}_{\mathrm{II}}=\frac{1}{2} d_{i j} d_{i j},
\end{gathered}
$$

где $\dot{\varepsilon}_{\text {II }}$ - второй инвариант тензора скорости деформаций, $d_{i j}$ - компоненты тензора скорости деформации, $T$ - температура, $A$ - масштабный коэффициент, $n$ - показатель нелинейности $(n=1$ для ньютоновской жидкости), $H$ - энергия активации. Параметры $A, n, H$ определяются из лабораторных экспериментов по деформации вещества разного состава, а их значения для пород приведены в табл. 1. При фиксированной температуре эффективная вязкость вещества снижается с ростом скорости деформации.

Для оценки величины вязкостной диссипации были получены стационарные решения. Так как поперечный размер Приенисейской сдвиговой зоны варьируется от 20 до 50 км, были проведены исследования влияния ширины зоны деформаций. Для этого был выполнен дополнительный расчет для случая, когда ширина сдвиговой зоны составляет 20 км. Установившееся распределение температуры показано на рис. 5 для ширины сдвиговой зоны 40 и 20 км. Здесь и далее на рисунках приводится только деформируемая центральная область модели, жесткие обрамляющие блоки не показаны. Повышение температуры в середине сдвиговой зоны относительно начальной геотермы вызвано вязкостной диссипацией тепла. Стоит отметить, что максимальный нагрев происходит в центре и уменьшается в краевых частях, так как происходит отвод тепла через окружающие блоки справа и слева, в которых 
деформации отсутствуют. Для вариантов модели с шириной сдвиговой зоны 40 и 20 км картина качественно повторяется, отличие состоит в максимальной температуре в гранулитовом слое, где она ниже в среднем на $80{ }^{\circ} \mathrm{C}$ для случая узкой сдвиговой зоны.

На рис. 6 приведено распределение эффективной вязкости в поперечном (фронтальном на рис. 2, в) разрезе в середине модели. Характерные скачки на границах слоев объясняются разными свойствами вещества разного состава. Картина распределения эффективной вязкости для варианта модели с 40-километровой сдвиговой зоной (рис. 6, а) напоминает структуру «рождественской елки» и в целом контролируется температурой. Уменьшение вязкости в середине области происходит в связи с диссипативным нагревом, что согласуется с результатами моделирования тепловыделения при сдвиге, включающем кору и мантийную литосферу [Leloup et al., 1999]. Распределение вязкости для варианта со сдвиговой зоной 20 км (рис. 6, б) становится более однородным в каждом слое. Эффективная вязкость в среднем ниже на один порядок в диоритовом и гранулитовом слое коры и сохранет минимальные
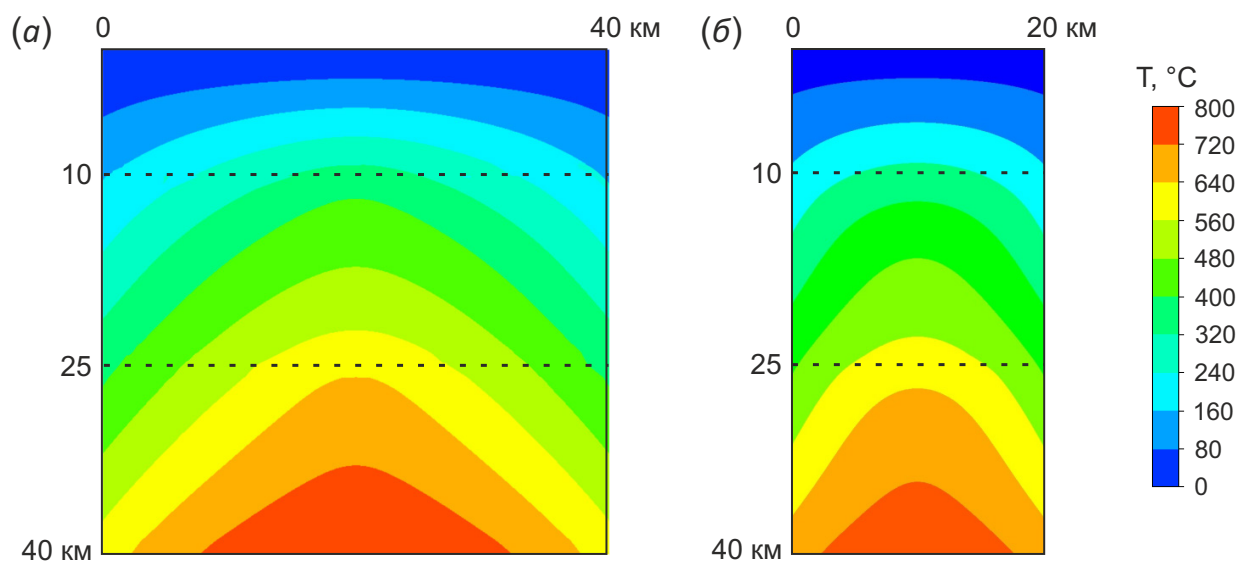

Рис. 5. Результат моделирования с учетом вязкостной диссипации тепла.

(a) - ширина сдвиговой зоны 40 км; (б) - ширина сдвиговой зоны 20 км. Показано установившееся распределение температуры в середине сдвиговой зоны (сечение х=80 км, см. рис. 2, в), разрез фронтальный. Показана деформируемая область модели. Штриховые линии показывают границы слоев коры.

Fig. 5. Simulation results taking into account the viscous dissipation.

Shown is the temperature distribution in the middle of the area ( $\mathrm{x}=80 \mathrm{~km})$, the section is frontal. The rise in temperature in the middle of the region relative to the initial geotherm is explained by viscous dissipation. The dashed lines show the boundaries between the layers of the crust. (a) - shear zone $40 \mathrm{~km}$ wide; (б) - shear zone $20 \mathrm{~km}$ wide.
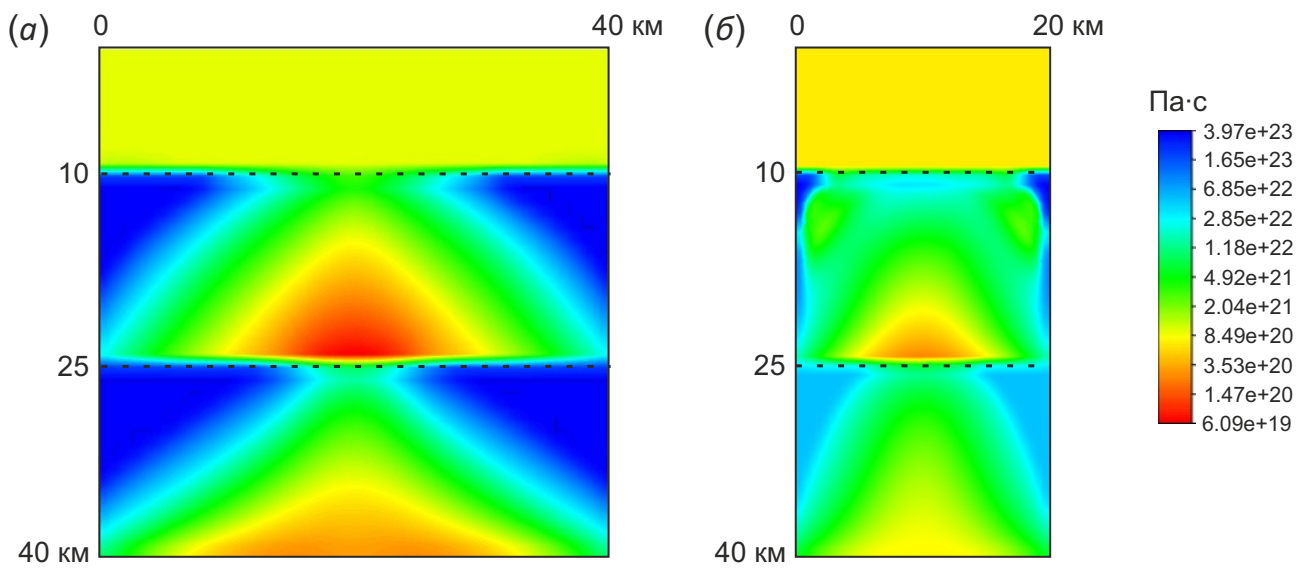

Рис 6. Стационарное распределение вязкости в сдвиговой зоне.

Показан фронтальный разрез в сечении х=80 км. Скачки вязкости по глубине объясняются расслоенностью коры, а изменения в слоях обусловлены температурной и кинематической зависимостью. Штриховые линии показывают границы между слоями коры. Шкала приведена в логарифмическом масштабе. (a) - ширина сдвиговой зоны 40 км; (б) - ширина сдвиговой зоны 20 км.

Fig. 6. Shown are the effective viscosity, frontal view in section $\mathrm{x}=80 \mathrm{~km}$.

Viscosity jumps with depth are explained by the layering of the crust, with changes in layers are due to temperature and strain-rate dependence. The dashed lines show the boundaries between the layers of the crust. ( $a$ ) - shear zone width $40 \mathrm{~km}$; (б) - shear zone width $20 \mathrm{~km}$. 
значения в центре основания каждого слоя и максимальные - на внешних охлажденных границах. Верхний наиболее охлажденный метапелитовый слой коры характеризуется не вязкой, а хрупкоупругой реологией [Burov, 2011], поэтому для него использование реологии вязкой жидкости некорректно. Ввиду вычислительных особенностей модели производилось искусственное ограничение вязкости вещества верхнего слоя коры. При слишком высоких значениях вязкости в верхнем метаосадочном слое $\left(10^{23}\right.$ Па·с и выше) возникают чрезмерно высокие напряжения, превышающие прочность пород. Чтобы корректно описать поведение вещества верхнего метаосадочного слоя, задавался верхний предел вязкости $10^{21}$ Па·с, который соответствует вязкости водонасыщенного кварцита при скорости деформации $10^{-14}\left(\mathrm{c}^{-1}\right)$ [Strehlau, Meissner, 1982]. В подобном подходе авторы [Schmeling et al., 2019] производили «усечение» интервала допустимых величин вязкости гранитной коры в диапазоне $\lg \eta(П а \cdot c)=$ =18-24, значение $\lg \eta($ Па·c)=21 попадает в середину этого диапазона. При вариации параметра вязкости верхнего метаосадочного слоя ниже $10^{21}$ Па·с влияние диссипативного нагрева в верхней коре несущественно.

Максимальные скорости деформаций фиксируются вблизи центральной осевой зоны, параллельной боковым границам. Распределение скоростей деформаций существенно неоднородно как по глубине, так и поперек сдвиговой зоны (рис. 7, а). Область максимальных скоростей деформаций локализована в зоне пониженной вязкости и повышенной температуры. Аномально высокие скорости в модели шириной 40 км концентрируются в районе границы нижней и средней коры и постепенно снижаются к поверхности и к периферии сдвиговой зоны (рис. 7, а). В случае сдвиговой зоны шириной 20 км, имеющей два локализованных пика в середине диоритового и гранулитового слоя (рис. 7,6$)$, распределение скоростей становится более однородным. Ширина этих пиков примерно 5 км и имеет максимальные значения на порядок меньше $\left(10^{-14} \mathrm{c}^{-1}\right)$, чем в случае сдвиговой зоны шириной 40 км $\left(10^{-13} \mathrm{c}^{-1}\right)$.

Распределения температуры (см. рис. 5), вязкости (см. рис. 6) и скоростей деформации (рис. 7) показывают сложную взаимозависимость, определяемую реологическим соотношением (5). Полученное стационарное решение соответствует термомеханическому равновесию многопараметрической системы, учитывающей нелинейную зависимость вязкости от температуры и скорости деформации. На это равновесие совместное влияние оказывают несколько разнонаправленных процессов: наибольшее выделение энергии должно происходить там, где напряжения и скорости деформации имеют наибольшие значения согласно диссипативному вкладу $\overline{\bar{\tau}}, \vec{v}$ в уравнении теплового баланса. При этом рост температуры приводит к снижению вязкости согласно (5), что, в свою очередь, вызывает снижение напряжений, и диссипативный нагрев прекращается. Модельное распределение вязкости в сдвиговой зоне говорит о том, что температура оказывает большее влияние, чем скорость деформации.

На рис. 8 приведены картины распределения диссипативного нагрева в трех проекциях. Как следует из моделирования, нагрев, вызванный вязкой диссипацией, локализован в области коры, где породы подвержены наибольшим деформациям и поддерживаются высокие напряжения. Для стационарной задачи со скоростью сдвига 2 см/год нагрев составляет $246{ }^{\circ} \mathrm{C}$. На продольном профиле (рис. 8, б) можно наблюдать, что область диссипативного нагрева имеет двуслойную структуру с двумя зонами локальных максимумов, расположенных в верхней части диоритового и гранулитового слоя. Это объясняется распределением вязкости (см. рис 6) и скорости деформации (см. рис 7). Максимальное приращение температуры происходит ниже границы гранулитового и диоритового слоев, где локализованы наибольшие скорости деформаций.
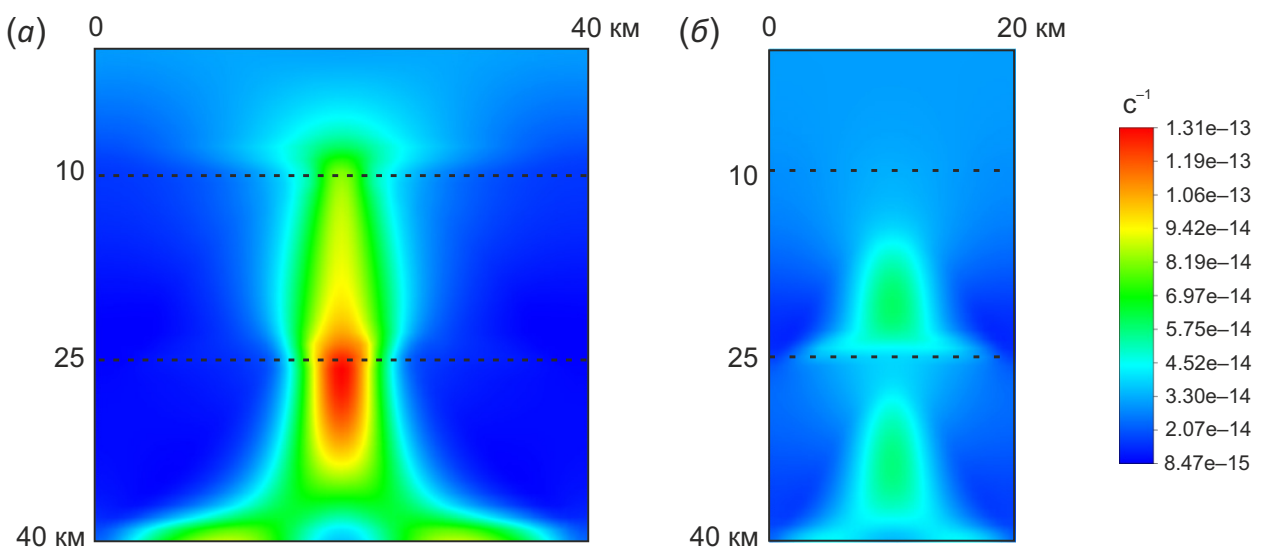

Рис. 7. Стационарное распределение скорости деформации (в единицах $\mathrm{c}^{-1}$ ) для расчета с учетом вязкой диссипации; разрез фронтальный (x=80 км). Штриховые линии показывают границы между слоями коры. (a) - ширина сдвиговой зоны 40 км, (б) - ширина сдвиговой зоны 20 км.

Fig. 7. Shown are the strain rate (in $\mathrm{c}^{-1}$ ) for model taking into account viscous dissipation; the section is frontal ( $\left.\mathrm{x}=80 \mathrm{~km}\right)$. The dashed lines show the boundaries between the layers of the crust. (a) - shear zone width $40 \mathrm{~km}$; (б) - shear zone width $20 \mathrm{~km}$. 
Асимметричный вид распределения температуры на горизонтальном срезе (рис. 8, в) в краевых областях модели отражает направление сдвиговых течений. На фронтальном сечении модели сдвиговой зоны шириной 20 км (рис. 8, г) максимальное приращение температуры составляет $170{ }^{\circ} \mathrm{C}$.

В дополнение к основным расчетам было проведено моделирование в случае движения со скоростью 4 см/год, число Бринкмана становится в четыре раза больше. В этом случае нагрев усиливается, рост пиковых температур достигает $310^{\circ} \mathrm{C}$. Области, соответствующие наибольшему нагреву, локализуются в верхних частях слоев, как и для случая движения 2 см/год. Эти расчеты показывают прямую зависимость величины вязкостного нагрева от критерия Бринкмана.

На рис. 9 приведено распределение температуры по глубине в центре расчетной области ( $\mathrm{x}=80$ км, $\mathrm{y}=$ $=20$ км) для случаев движения блоков со скоростью сдвига 2 и 4 см/год. Линии, показывающие приращение температуры, имеют два локальных максимума на глубине 10 и 25 км. Эти зоны соответствуют областям с наибольшими скоростями деформации и малой вязкостью (см. рис. 6, 7), в которых происходит наибольший рост температуры. С ростом глубины диссипативный нагрев практически не меняется.

Второй тип расчета был выполнен в нестационарной постановке. Стационарное решение позволяет оценить предельные значения температуры с учетом вязкостной диссипации, а нестационарное - определить, за какое время достигается предельная температура. Нестационарная модель, с одной стороны, позволяет проверить, достижимы ли предельные значения температур из стационарного расчета за геологически приемлемые времена, а с другой - получить оценки длительности деформаций. Результаты, полученные в нестационарной модели (рис. 10), показывают, как $(a)$

40 к

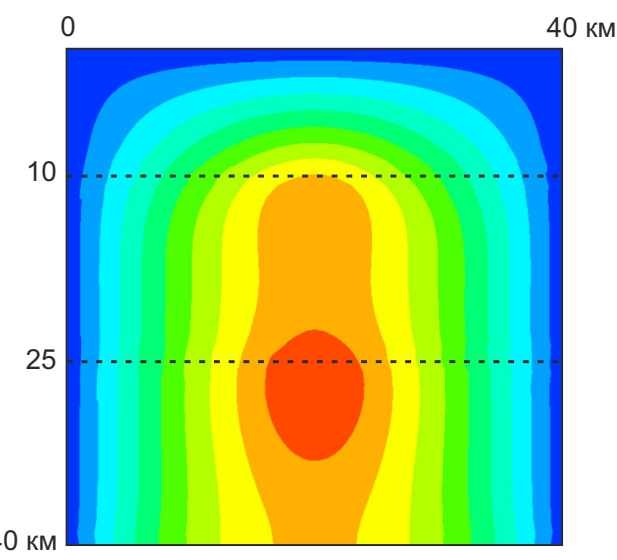

(2)

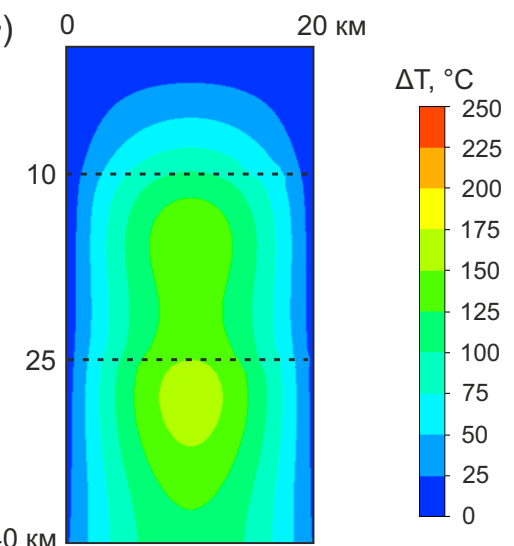

160 км

(б)

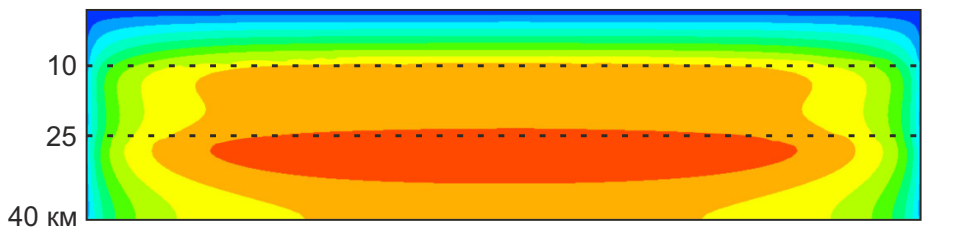

(в) 40 км

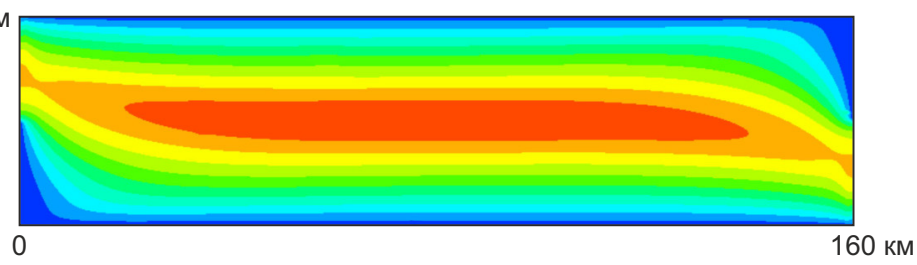

Рис. 8. Результаты 3D моделирования диссипативного нагрева (приведена разность между температурой, рассчитанной с учетом и без учета вязкой диссипации) для стационарной задачи для вариантов при 40-километровой $(a, 6,8)$ и 20 -километровой зоне (2). Картина распределения диссипативного нагрева, максимальный нагрев $246^{\circ} \mathrm{C}$.

$(a)$ - фронтальный вид в сечении $\mathrm{x}=80$ км; (б) - продольный вид в сечении у=20 км; ( 8 ) - горизонтальное сечение на глубине $\mathrm{z}=27$ км, где достигался наибольший нагрев; (2) - картина распределения диссипативного нагрева при ширине сдвиговой зоны 20 км. Показан фронтальный вид в сечении $\mathrm{x}=80$ км, максимальный нагрев $170{ }^{\circ} \mathrm{C}$. Штриховые линии показывают границы между слоями коры.

Fig. 8. Results of 3D modeling of viscous dissipation (shear heating). The difference between the temperature calculated with and with no regard to viscous dissipation is shown for the stationary problem.

(a) - frontal view in section $\mathrm{x}=80 \mathrm{~km}$; (6) - longitudinal view in section $\mathrm{y}=20 \mathrm{~km},(\mathrm{\theta})$ - horizontal section at a depth of $\mathrm{z}=27 \mathrm{~km}$, where heating attained its maximum. (2) - frontal view in section $\mathrm{x}=80 \mathrm{~km}$, the width of the strike-slip zone is $20 \mathrm{~km}$, maximum heating $170{ }^{\circ} \mathrm{C}$. The dashed lines show the boundaries between the layers of the crust. 


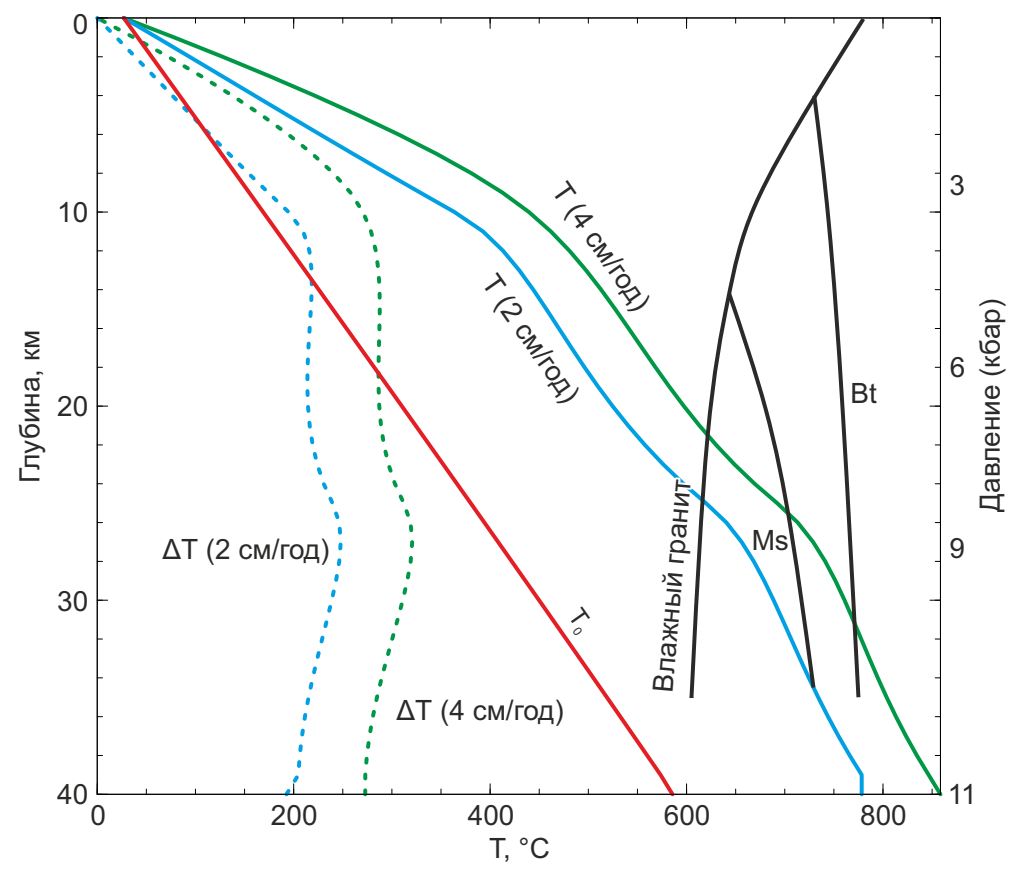

Рис 9. Распределение температуры по глубине в центре расчетной области ( $\mathrm{x}=80$ км, $\mathrm{y}=20$ км) для случаев движения со скоростью 2 и 4 см/год при ширине сдвиговой зоны 40 км, пунктирными линиями показано приращение температуры $\Delta T$ вследствие диссипативного тепловыделения.

Обозначения кривых корового плавления: влажный гранит - водонасыщенный метапелитовый солидус; Мs - плавление при дегидратации мусковита Mus+Alb+Q $\rightarrow \mathrm{Ksp}+\mathrm{Als}+\mathrm{L} ; \mathrm{Bt}-$ плавление при дегидратации биотита (Bio+Als+Pl+Q $\rightarrow \mathrm{Gar}+\mathrm{Ksp}+\mathrm{L})($ по [Thompson, 1982]).

Fig 9. Vertical temperature profile in the center of the computational domain ( $\mathrm{x}=80 \mathrm{~km}, \mathrm{y}=20 \mathrm{~km})$ for slip rates of 2 and $4 \mathrm{~cm} / \mathrm{year}$ over a $40 \mathrm{~km}$ wide shear zone, dotted lines show the temperature increment $(\Delta T)$ due to dissipative heat release.

Designation of crustal melting curves: влажный гранит (wet granite) - water-saturated metapelite solidus; Ms - muscovite dehydration-melting reaction; Mus $+\mathrm{Alb}+\mathrm{Q} \rightarrow \mathrm{Ksp}+\mathrm{Als}+\mathrm{L}$; Bt - biotite dehydration-melting reaction $(\mathrm{Bio}+\mathrm{Als}+\mathrm{Pl}+\mathrm{Q} \rightarrow \mathrm{Gar}+\mathrm{Ksp}+\mathrm{L})(\mathrm{after}$ [Thompson, 1982]).

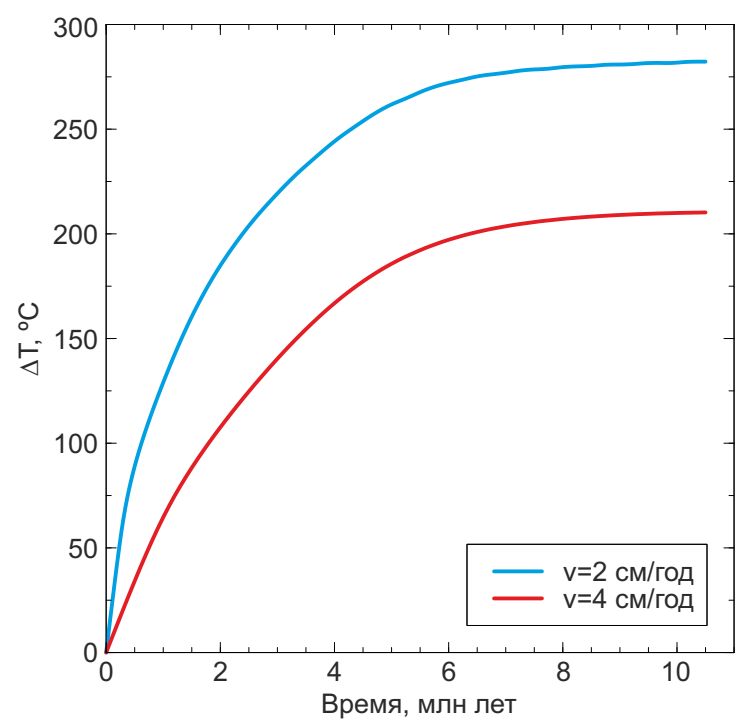

Рис. 10. Рост температуры при вязкой диссипации на глубине 20 км в центре расчетной области (в точке с координатами х= $=80$ км, y=20 км, z=20 км). При длительности вязких деформаций в течение 6-7 млн лет достигаются предельные (стационарные) температуры диссипативного нагрева.

Fig. 10. Temperature increase during viscous dissipation at a depth of $20 \mathrm{~km}$ in the center of the computational domain (at a point with coordinates $\mathrm{x}=80 \mathrm{~km}, \mathrm{y}=20 \mathrm{~km}, \mathrm{z}=20 \mathrm{~km}$ ). The 6-7 million-year-duration viscous deformations provide the ultimate (stationary) temperatures of dissipative heating. 


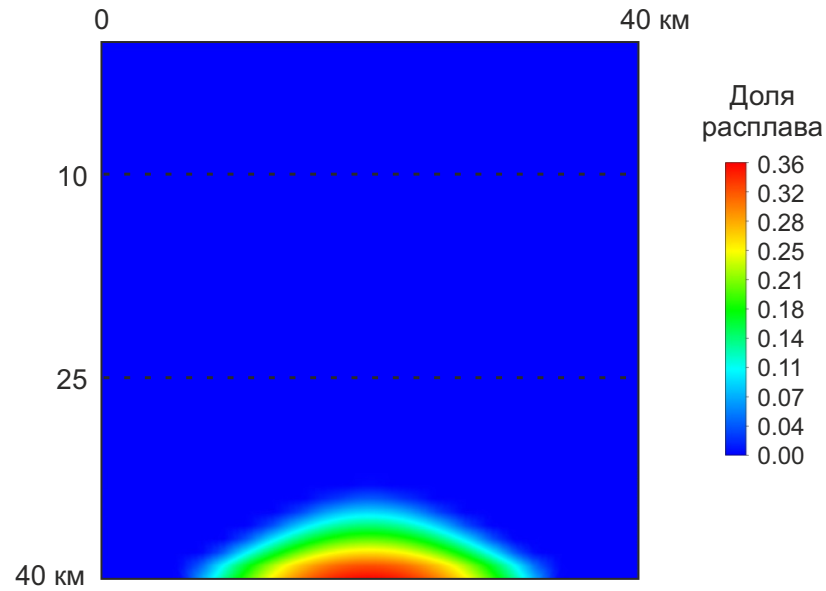

Рис. 11. Результаты моделирования с учетом плавления и вязкостной диссипации.

Показано распределение доли расплава для стационарного состояния; разрез фронтальный (х=80 км). Штриховые линии показывают границы между слоями коры.

Fig. 11. Simulation results for the stationary problem taking into account the partial melting and viscous dissipation.

The distribution of the melt fraction is shown; the section is frontal $(\mathrm{x}=80 \mathrm{~km})$. The dashed lines show the boundaries between the crustal layers.

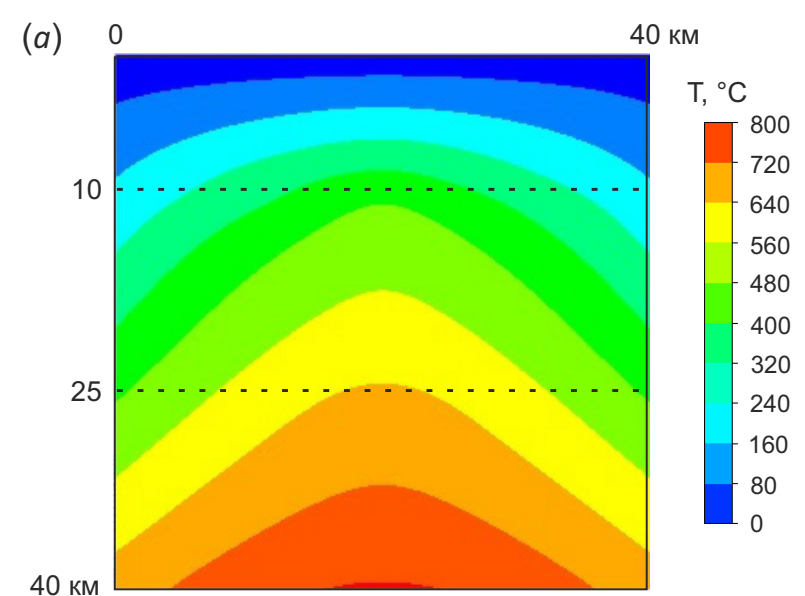

(в) 0

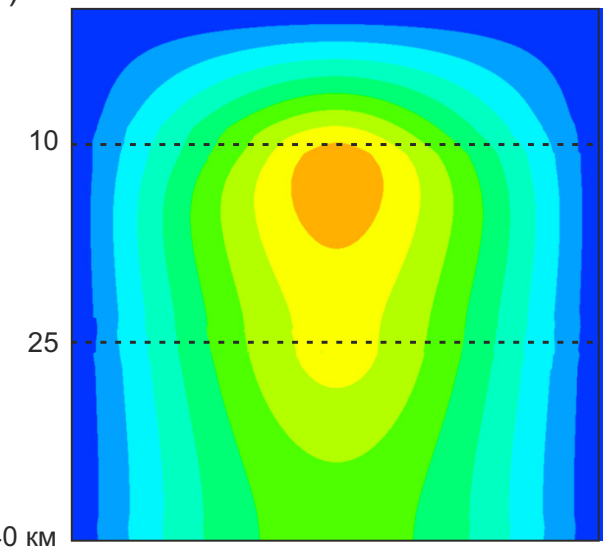

$40 \mathrm{KM}$

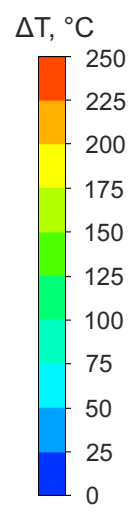

(б)

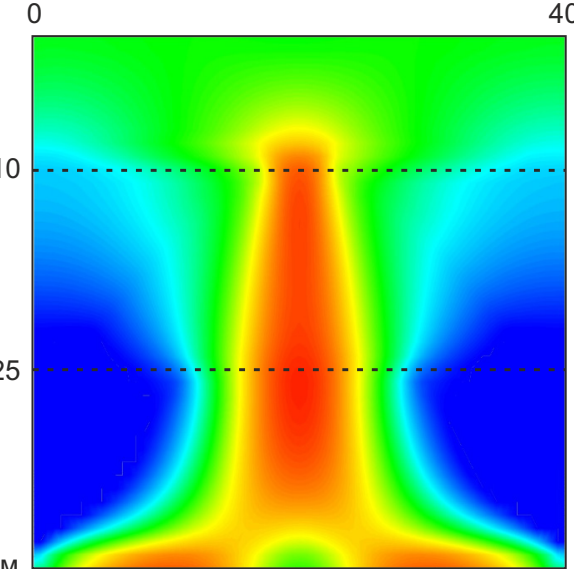

40 км

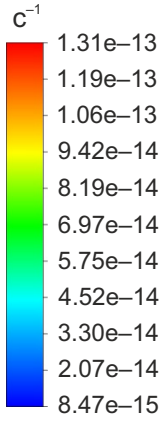

$40 \mathrm{KM}$

(2) 0

40 км

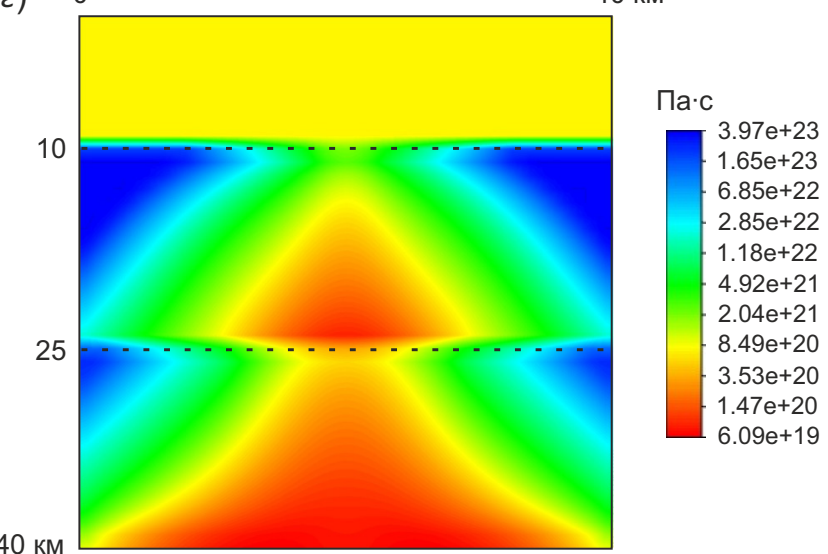

Рис. 12. Результаты моделирования для стационарной задачи с учетом плавления и вязкостной диссипации, фронтальный вид в сечении $\mathrm{x}=80$ км.

(a) - температура с учетом диссипативного нагрева; (б) - скорость деформации; (в) - величина нагрева при вязкостной диссипации; (2) - картина распределения вязкости.

Fig. 12. Simulation results for the stationary problem taking into account the melting and viscous dissipation, frontal view in the section $\mathrm{x}=80 \mathrm{~km}$.

(a) - temperature with allowance for dissipative heating; (б) - strain rate; ( 8 ) - temperature increase at viscous dissipation; ( 2 ) - viscosity field. 
нарастает температура со временем на глубине 25 км в центре расчетной области. Увеличение температуры за счет вязкой диссипации достигает 210 и $280{ }^{\circ} \mathrm{C}$ за 10 млн лет при $1 / 2$ скорости сдвига 2 и 4 см/год соответственно. Эти данные показывают, что за первые 5 млн лет рост температуры составляет $90 \%$, а за время 6-7 млн лет практически достигаются предельные значения температуры независимо от скорости движения блоков. При этом темп роста температуры падает со временем.

Для исследования влияния плавления и наличия жидкой фазы на диссипативный нагрев были внесены изменения в закон вязкого течения - добавлен множитель $\exp \left(\frac{-c \varphi}{n}\right)$, где - $\varphi$ доля расплава, $c$ - эмпирический коэффициент, $n$ - как в (5) [Polyansky et al., 2019b].

Согласно модифицированному соотношению (5) в реологической модели «эффективная» вязкость является функцией состава, температуры и наличия расплава:

$$
\eta=A^{\frac{-1}{n}}\left[\varepsilon_{I I}^{\circ}\right]^{\frac{1-n}{n}} \exp \left(\frac{H}{n R T}\right) \exp \left(\frac{-c \varphi}{n}\right)
$$

В качестве параметров плавления коры были взяты температуры солидуса $t_{\text {sol }}=650{ }^{\circ} \mathrm{C}$ и ликвидуса $t_{\text {liq }}=$ $=850{ }^{\circ} \mathrm{C}$, учитывалась скрытая теплота плавления $L=$ $=380$ кДж/кг. Такие параметры были выбраны как отвечающие случаю наиболее легкоплавкого вещества коры, соответствующие температуре плавления «влажного» гранита [Thompson, 1982]. Таким образом, принятые в модели параметры плавления позволяют дать самые «оптимистичные» оценки степеней плавления коры. Доля расплава устанавливалась линейной функцией от температуры в интервале от температур солидуса-ликвидуса.

Результаты моделирования показаны на рис. 11 и 12. На рис. 11 приведена картина распределения доли расплава для стационарной задачи с учетом вязкостной диссипации. В основании коры можно ожидать появление расплава с объемной долей 30-35 \%. На рис. 12 показаны картины распределения для стационарной задачи с учетом вязкостной диссипации и учетом присутствия расплава. Основное отличие от результатов без учета плавления состоит в величине нагрева и размере области вязкостной диссипации тепла (рис. 12, в). В расчетах без учета плавления присутствовало две локализованных зоны, в то время как при условиях плавления основная область нагрева сосредоточена в верхней части диоритового слоя. Величина нагрева в средней коре остается такой же ввиду отсутствия расплава. Нагрев в верхней части гранулитового слоя, где в расчете без учета расплава был пик, уменьшился, так как из-за появления расплава произошел сброс напряжений, и это привело к уменьшению выделяемого тепла. Скорость деформации в абсолютных значениях выросла на 10 \%, а область с максимальными значениями увеличилась от примерно 10 км до 12-13 км (рис. 12, б).
В гранулитовом слое картина деформирования изменилась: область с максимальными значениями скорости деформации распространилась на зону плавления в его основании.

\section{5. ОБСУЖДЕНИЕ}

В зонах дислокационного метаморфизма ПРСЗ зафиксированы отклонения РТ-параметров от фоновых значений, соответствующих литостатическому давлению и стандартной геотерме, характерной для соседних блоков коры Енисейского кряжа.

Приенисейская региональная сдвиговая зона окончательно сформировалась к рубежу 600 млн лет, установленному по возрасту высокобарных тектонитов [Likhanov et al., 2021]. По данным [Vernikovskaya et al., 2009; Likhanov, Santosh, 2019], в Центрально-Ангарском блоке на этапе 750-720 млн лет происходило внедрение высокотемпературных гранитных магм $\left(\mathrm{T} \geq 800^{\circ} \mathrm{C}\right)$ и формирование лейкогранитных массивов А-типа Глушихинского комплекса (Гаревский, Лендахский, Глушихинский, Стрелковский, Чернореченский). По результатам ${ }^{40} \mathrm{Ar} /{ }^{39} \mathrm{Ar}$ датирования бластомилонитов в зоне сочленения палеоконтинентального и палеоокеанического секторов установлено, что метапелиты и метабазиты подвергались интенсивным деформациям с перекристаллизацией субстрата и образованием комплексов бластомилонитов в интервале 637-595 млн лет [Likhanov et al., 2021], поэтому ввиду более древнего возраста гранитных массивов магматическое тепло не может рассматриваться в качестве теплового источника при образовании более поздних тектонитов, содержащих высокотемпературные и высокобарические минеральные ассоциации. По этой же причине не может рассматриваться в качестве теплового источника повышенное тепловыделение от радиогенных элементов $(\mathrm{U}, \mathrm{Th}, \mathrm{K})$ в син- и постколлизионных гранитоидах Татарско-Ишимбинской разломной зоны 3.2-6.2 мкВт/м ${ }^{3}$ при средней величине 1.73 мкВт/м³ во вмещающих породах [Vernikovsky et al., 2011]. Мы предполагаем, что механизмом, приводящим к наблюдаемым метаморфическим градиентам, может являться диссипативный нагрев вещества в результате трения и/или вязкопластических деформаций, рассматриваемый в ряде работ [Leloup et al., 1999; Burg, Gerya, 2005; He et al., 2009; Nabelek et al., 2010; Hobbs et al., 2011; Mako, Caddick, 2018; Hughes et al., 2020].

В истории формирования Приенисейского структурного шва выделяются несколько этапов, характеризующихся разной геодинамической обстановкой [Kozlov et al., 2020]. В соответствии со сменой тектонического режима от субдукционного к коллизионному и постколлизионно-сдвиговому нами рассмотрены три основные термомеханические модели, которые отражают тип преобладающих деформаций. Первая модель характеризует субдукционно-обдукционные процессы, в результате которых произошел подъем и надвигание исаковских офиолитов в западной части Приенисейского структурного шва. По-видимому, деформационные 
процессы на субдукционно-обдукционных контактах блоков проходили в присутствии флюида, выделившегося из водосодержащих минералов, о чем говорят находки реликтов глаукофана в апометабазитовых тектонитах шовной зоны [Likhanov, Savko 2019]. Результаты, полученные по надвиго-обдукционной модели с глубиной детачмента 30 км, дают оценки величины диссипативного нагрева на $190{ }^{\circ} \mathrm{C}$ при коэффициенте трения 0.3 при контакте тектонических пластин. Полученные модельные оценки близки к нижним значениям диапазона роста температуры $180-240{ }^{\circ} \mathrm{C}$ при формировании апоглаукофановых бластомилонитов шовной зоны Исаковского блока [Likhanov et al., 2021].

Дискуссионным является вопрос о соотношении величины тепловыделения при трении на контактах сдвиговых разломов либо при вязких деформациях в зонах тектонического течения и бластомилонитизации [Sibson, 1977; Chikov et al., 1988]. Для этих двух типов сдвиговых зон нами выполнено моделирование в 3-мерной постановке. Модели учитывают в первом случае только фрикционное тепло на контакте блоков, а во втором варианте рассматривается диссипация тепла при вязком течении в 20-40-километровом массиве деформируемых пород, ограниченном жесткими блоками. И в одном, и в другом варианте модель предсказывает значимый нагрев (более $100{ }^{\circ} \mathrm{C}$ ). В модели одиночного вертикального разлома нагрев происходит только в его наиболее глубинной части в основании коры, где касательные напряжения максимальны. Однако, по современным представлениям о вертикальной зональности дизьюнктивов [Sklyarov, 2001], хрупкоупругое поведение вещества характерно для верхней коры, поэтому, как нам представляется, более реалистичной для рассматриваемых глубин (давление выше 6-8 кбар) является модель вязкого деформирования сдвиговой зоны конечной ширины с учетом реологической расслоенности коры.

Ключевыми факторами являются продолжительность активности сдвиговой зоны и скорость перемещения контактирующих блоков, определяющие амплитуду сдвиговых перемещений. Величина перемещений по надвиговым и сдвиговым разломам ПРСЗ составляет десятки километров по данным [Postelnikov, 1980; Vernikovsky et al., 2003]. Полученные результаты моделирования дают предварительную оценку величины диссипативного разогрева пород Приенисейской коллизионно-сдвиговой зоны ввиду неопределенности данных о кинематических параметрах.

Полученные в модели сдвиговой зоны геотермические кривые (см. рис. 3, в, рис. 9) говорят о достижении солидуса влажного пелита, а в случае повышенных скоростей сдвига - достижении температуры дегидратации мусковита и биотита. Эти оценки допускают возможность частичного плавления кислого корового материала в пределах утолщенной до 50 км коры Енисейского кряжа [Salnikov, 2009]. В связи с возможностью плавления были проведены исследования влияния жидкой фазы на способность деформируемой среды к выделению тепла при вязком течении. Важно отметить, что наличие расплава как отдельной фазы в ранее разработанных моделях вязкой диссипации тепла не учитывалось [Burg, Gerya, 2005; Mako, Caddick, 2018]. Рассматривалась возможность достижения условий частичного плавления из-за диссипативного нагрева, однако термомеханическая обратная связь, т.е. влияние появившегося расплава на снижение вязкости или прочности пород, обсуждалась лишь на качественном уровне [Nabelek et al., 2010]. Наши результаты показывают, что как только формируется частичный расплав, происходит падение вязкости и эффективность диссипативного нагрева резко снижается. В нижней коре величина диссипативного нагрева при участии расплава составляет $125-175^{\circ} \mathrm{C}$, а в его отсутствие достигает $250{ }^{\circ} \mathrm{C}$.

Отсутствие гранитных интрузий соответствующего возраста в областях бластомилонитизации палеоокеанической и палеоконтинентальной зоны ПРСЗ [Likhanov et al., 2021] ставит под сомнение достижимость условий плавления. По-видимому, предшествующий эпизод гранитоидного магматизма на этапе 750-720 млн лет привел к истощению областей магмогенерации в средней - нижней коре легкоплавкими и летучими компонентами, и повторное плавление в коре ПРСЗ на этапе дислокационного метаморфизма 640-600 млн лет не произошло. Сравнение с модельными результатами позволяет заключить, что наиболее реальными параметрами являются низкие коэффициенты трения (0.3) в разломах и умеренные скорости сдвиговых деформаций (не более 2 см/год) в дизъюнктивных структурах ПРСЗ.

\section{6. ЗАКЛЮЧЕНИЕ}

Выполненное трехмерное моделирование процессов вязкопластических деформаций в ПРСЗ позволяет количественно оценить эффект диссипативного нагрева в разных геодинамических обстановках. Модель вязкого деформирования сдвиговой зоны конечной ширины с учетом реологической расслоенности коры предсказывает диссипативный нагрев на 200-310 ${ }^{\circ} \mathrm{C}$ в режиме вертикального сдвига области коры при скорости деформации 2-4 см/год. Модель обдукции тектонической пластины со скоростью надвигания 5 см/год дает оценки нагрева пород при трении на контакте блоков не более $130-190^{\circ} \mathrm{C}$. Характерное время установления стационарного режима диссипативного нагрева составляет 6-8 млн лет.

Соотношение коэффициента трения и нормальных напряжений (глубины) на контактах тектонических блоков играет определяющую роль в процессе тепловыделения и диссипации тепла в зоне разлома. Принимая во внимание геологические оценки коэффициента трения не более 0.17-0.25 [Bird, Kong, 1994], можно установить, что тепловыделение при сдвиговых деформациях не обеспечило повышения температуры в зоне надвиговых разломов Исаковского блока до условий плавления метабазитов. 
Метапелиты и тектониты палеоконтинентальной части Приенисейской региональной сдвиговой зоны испытали температурное воздействие за счет тепла трения / вязких деформаций на уровне амфиболитовой фации $\left(600-700^{\circ} \mathrm{C}\right)$, но условия частичного плавления влажного гранита не достигались. Моделирование показывает, что, как только формируется частичный расплав, происходит падение вязкости и эффективность диссипативного нагрева существенно снижается. По-видимому, этим объясняется субсолидусный характер бластомилонитизации и отсутствие магматических событий в рассматриваемом возрастном интервале.

\section{7. ЛИТЕРАТУРА / REFERENCES}

ANSYS Fluent Theory Guide, 2013. Release 15.0. ANSYS Inc., USA, $779 \mathrm{p}$.

Aydin 0., 2005. Effects of Viscous Dissipation on the Heat Transfer in Forced Pipe Flow. Part 1: Both Hydrodynamically and Thermally Fully Developed Flow. Energy Conversion and Management 46 (5), 757-769. https://doi.org/10.10 16/j.enconman.2004.05.004.

Barr T.D., Dahlen F.A., 1989. Brittle Frictional Mountain Building: 2. Thermal Structure and Heat Budget. Journal of Geophysical Research: Solid Earth 94 (B4), 3923-3947. https://doi.org/10.1029/JB094iB04p03923.

Bea F., 2012. The Sources of Energy for Crustal Melting and the Geochemistry of Heat-Producing Elements. Lithos 153, 278-291. https://doi.org/10.1016/j.lithos.20 12.01.017.

Bird P., Kong X., 1994. Computer Simulations of California Tectonics Confirm Very Low Strength of Major Faults. Geological Society of America Bulletin 106 (2), 159-174. https:// doi.org/10.1130/0016-7606(1994)106<0159:CSOCTC> 2.3.CO;2.

Burg J.-P., Gerya T.V., 2005. The Role of Viscous Heating in Barrovian Metamorphism: Thermomechanical Models and Application to the Lepontine Dome in the Central Alps. Journal Metamorphic Geology 23 (2), 75-95. https://doi. org/10.1111/j.1525-1314.2005.00563.x.

Burov E.B., 2011. Rheology and Strength of the Lithosphere. Marine and Petroleum Geology 28 (8), 1402-1443. https://doi.org/10.1016/j.marpetgeo.2011.05.008.

Byerlee J., 1978. Friction of Rocks. Pure and Applied Geophysics Volume 116, 615-626. https://doi.org/10.10 07/BF00876528.

Chikov B.M., Zinoviev S.V., Podtsibastenkova E.A., 1988. Morphological Types of Flow Structures in Blastomylonites of the Irtysh Shear Zone. Russian Geology and Geophysics 8, 11-14 (in Russian) [Чиков Б.М., Зиновьев С.В., Подцибастенкова Е.А. Морфологические типы структур течения в бластомилонитах Иртышской зоны смятия // Геология и геофизика. 1988. Т. 8. С. 11-14].

Cordonnier B., Schmalholz S.M., Hess K.-U., Dingwell D.B., 2012. Viscous Heating in Silicate Melts: An Experimental and Numerical Comparison. Journal of Geophysical Research: Solid Earth 117 (B2). https://doi.org/10.1029/20 10JB007982.
Hansen F.D., Carter N.L., 1982. Creep of Selected Crustal Rocks at 1000 MPa. American Geophysical Union 63, p. 437.

He J., Lu Sh., Wang X., 2009. Mechanical Relation between Crustal Rheology, Effective Fault Friction, and StrikeSlip Partitioning among the Xiaojiang Fault System, Southeastern Tibet. Journal of Asian Earth Sciences 34 (3), 363375. https://doi.org/10.1016/j.jseaes.2008.06.003.

Hobbs B.E., Ord A., Regenauer-Lieb K., 2011. The Thermodynamics of Deformed Metamorphic Rocks: A Review. Journal of Structural Geology 33 (5), 758-818. https:// doi. org/10.1016/j.jsg.2011.01.013.

Hughes A., Kendrick J.E., Lamur A., Wadsworth F.B., Wallace P.A., Di Toro G., Lavallée Y., 2020. Frictional Behaviour, Wear and Comminution of Synthetic Porous Geomaterials. Frontiers in Earth Science 8, 562548. https:// doi.org/10.3389/feart.2020.562548.

Izokh A.E., Tran T.H., Polyakov G.V., Ngo T.P., Tran Tuan Anh, Travin A.V., 2004. Syn-Kinematic Ultramafic-Mafic Magmatism in the Red River Shear Zone. Journal of Geology. Series B (23), 26-41.

Kelsey D.E., Hand M., 2015. On Ultrahigh Temperature Crustal Metamorphism: Phase Equilibria, Trace Element Thermometry, Bulk Composition, Heat Sources, Timescales and Tectonic Settings. Geoscience Frontiers 6 (3), 311-356. https://doi.org/10.1016/j.gsf.2014.09.006.

Korobeynikov S.N., 2000. Non-linear Deformation of Solid Bodies. Publishing House of SB RAS, Novosibirsk, 262 p. (in Russian) [Коробейников С.Н. Нелинейное деформирование твердых тел. Новосибирск: Изд-во СО PAH, 2000. 262 c.].

Korobeynikov S.N., Reverdatto V.V., Polyanskii O.P., Sverdlova V.G., Babichev A.V., 2009. Computer Simulation of Underthrusting and Subduction due to Collision of Slabs. Numerical Analysis and Applications 2, 58-73. https://doi. org/10.1134/S1995423909010066.

Korobeynikov S.N., Reverdatto V.V., Polyanskii O.P., Sverdlova V.G., Babichev A.V., 2011. Influence of the Choice of a Rheological Law on Computer Simulation Results of Slab Subduction. Numerical Analysis and Applications 4, 56-70. https://doi.org/10.1134/S199542391101006X.

Kozlov P.S., Filippov Y.F., Likhanov I.I., Nozhkin A.D., 2020. Geodynamic Model of the Neoproterozoic Evolution of the Yenisei Paleosubduction Zone (Western Margin of the Siberian Craton), Russia. Geotectonics 54 (1), 54-67. https: // doi.org/10.1134/S0016852120010069.

Kozlov P.S., Likhanov I.I., Reverdatto V.V., Zinoviev S.V., 2012. Tectonometamorphic Evolution of the Garevka Polymetamorphic Complex (Yenisei Ridge). Russian Geology and Geophysics 53 (11), 1133-1149. https://doi.org/10.1016/ j.rgg.2012.09.002.

Leloup P., Ricard Y., Battaglia J., Lacassin R., 1999. Shear Heating in Continental Strike-Slip Shear Zones: Model and Field Examples. Geophysical Journal International 136 (1), 1940. https://doi.org/10.1046/j.1365-246X.1999.00683.x.

Likhanov I.I., Nozhkin A.D., Savko K.A., 2018. Accretionary Tectonics of Rock Complexes in the Western Margin of the Siberian Craton. Geotectonics 52, 22-44. https://doi. org/10.1134/S0016852118010107. 
Likhanov I.I., Santosh M., 2019. A-Type Granites in the Western Margin of the Siberian Craton: Implications for Breakup of the Precambrian Supercontinents Columbia/ Nuna and Rodinia. Precambrian Research 328, 128-145. https://doi.org/10.1016/j.precamres.2019.04.018.

Likhanov I.I., Savko K.A., 2019. First Data on the Nature and Age of the Protolith of High-Pressure Tectonites of Yenisei Ridge: A Link to the Early Stage of Formation of the Paleoasian Ocean. Doklady Earth Sciences 484 (6), 739-744. https://doi.org/10.31857/S0869-56524846739-744.

Likhanov I.I., Zinoviev S.V., Kozlov P.S., 2021. Blastomylonite Complexes of the Western Yenisei Ridge (Eastern Siberia, Russia): Geological Position, Metamorphic Evolution and Geodynamic Models. Geotectonics 55, 36-57. https://doi.org/10.1134/S0016852121010076.

Lockner D.A., Okubo P.G., 1983. Measurements of Frictional Heating in Granite. Journal of Geophysical Research: Solid Earth 88, 4313-4320. https://doi.org/10.1029/JB0 88iB05p04313.

Mako C.A., Caddick M.J., 2018. Quantifying Magnitudes of Shear Heating in Metamorphic Systems. Tectonophysics 744, 499-517. https://doi.org/10.1016/j.tecto.2018.07.003.

Mori H., Wallis S., Fujimoto K., Shigematsu N., 2015. Recognition of Shear Heating on a Long-Lived Major Fault Using Raman Carbonaceous Material Thermometry: Implications for Strength and Displacement History of the MTL, SW Japan. Island Arc 24 (4), 425-446. https://doi.org/10. 1111/iar.12129.

Nabelek P.I., Whittington A.G., Hofmeister A.M., 2010. Strain Heating as a Mechanism for Partial Melting and Ultrahigh Temperature Metamorphism in Convergent Orogens: Implications of Temperature-Dependent Thermal Diffusivity and Rheology. Journal of Geophysical Research: Solid Earth 115 (B12). https://doi.org/10.1029/2010JB007727.

Polyansky O.P., Kargopolov S.A., Babichev A.V., Reverdatto V.V., 2019a. High-Grade Metamorphism and Anatexis in the Teletskoe-Chulyshman Belt (Gorny Altai): U-Pb Geochronology, P-T Estimates, and Thermal Tectonic Model. Russian Geology and Geophysics 60 (12), 1425-1443. https: // doi.org/10.15372/RGG2019108.

Polyansky O.P., Kargopolov S.A., Izokh A.E., Semenov A.N., Babichev A.V., Vasilevsky A.N., 2019b. The Role of Magmatic Heat Sources in the Formation of Regional and Contact Metamorphic Areas in West Sangilen (Tuva, Russia). Geodynamics \& Tectonophysics 10 (2), 309-323 (in Russian) [Полянский О.П., Каргополов С.А., Изох А.Е., Семенов А.Н., Бабичев А.В., Василевский А.Н. Роль магматических источников тепла при формировании регионального и контактовых метаморфических ареалов Западного Сангилена (Тува) // Геодинамика и тектонофизика. 2019. Т. 10. № 2. C. 309-323]. https://doi.org/10.5800/GT-2019-10-2-0416.

Polyansky O.P., Korobeinikov S.N., Babichev A.V., Reverdatto V.V., Sverdlova V.G., 2014. Numerical Modeling of Mantle Diapirism as a Cause of Intracontinental Rifting. Izvestiya. Physics of the Solid Earth 50, 839-852. https:// doi.org/10.1134/S1069351314060056.

Postelnikov E.S., 1980. Geosynklinal Development of the Yenisei Ridge during the Late Precambrian. Proceedings of the Geological Institute of the USSR Academy of Science. Iss. 341. Nauka, Moscow, 70 p. (in Russian) [Постельников Е.С. Геосинклинальное развитие Енисейского кряжа в позднем докембрии // Труды ГИН АН СССР. М.: Наука, 1980. Вып. 341.70 с.].

Raleigh C.B., Kirby S.H., Carter N.L., Avé Lallemant H.G., 1971. Slip and the Clinoenstatite Transformation as Competing Rate Processes in Enstatite. Journal of Geophysical Research 76 (17), 4011-4022. https://doi.org/10.1029/ JB076i017p04011.

Rosen O.M., Condie K.C., Natapov L.M., Nozhkin A.D., 1994. Archean and Early Protezoic Evolution of the Siberian Craton: A Preliminary Assessment. Archean Crustal Evolution. Developments in Precambrian Geology 11, 411-459. https://doi.org/10.1016/S0166-2635(08)70228-7.

Salnikov A.S., 2009. Seismological Structure of the Earth's Crust of Platform and Folded Areas of Siberia on the Data from Regional Seismic Studies by the Refracted Waves Method. SNIIGGMS Publishing House, Novosibirsk, 131 p. (in Russian] [Сальников A.C. Сейсмологическое строение земной коры платформенных и складчатых областей Сибири по данным региональных сейсмических исследований преломленными волнами. Новосибирск: Издво СНИИГГиМС, 2009. 131 с.].

Schmeling H., Marquart G., Weinberg R., Wallner H., 2019. Modelling Melting and Melt Segregation by Two-Phase Flow: New Insights into the Dynamics of Magmatic Systems in the Continental Crust. Geophysical Journal International 217 (1), 422-450. https://doi.org/10.1093/gji/ggz029.

Semenov A.N., Polyansky O.P., 2017. Numerical Modeling of the Mechanisms of Magma Mingling and Mixing: A Case Study of the Formation of Complex Intrusions. Russian Geology and Geophysics 58 (11), 1317-1332. https://doi.org/ 10.1016/j.rgg.2017.11.001.

Sibson R.H., 1977. Fault Rocks and Fault Mechanism. Journal of the Geological Society 133, 191-213. https:// doi.org/10.1144/gsjgs.133.3.0191.

Sklyarov E.V. (Ed.), 2001. Metamorphism and Tectonics. Textbook. Intermet Engineering, Moscow, 216 p. (in Russian) [Метаморфизм и тектоника: Учебное пособие / Ред. Е.В. Скляров. М.: Интермет Инжиниринг, 2001. 216 с.].

Strehlau J., Meissner R., 1982. Limits of Stresses in Continental Crusts and Their Relation to the Depth-Frequency Distribution of Shallow Earthquakes. Tectonics 1 (1), 7389. https://doi.org/10.1029/TC001i001p00073.

Strong D.F., Hanmer S.K., 1981. The Leucogranites of Southern Brittany: Origin by Faulting, Frictional Heating, Fluid Flux and Fractional Melting. The Canadian Mineralogist 19 (1), 163-176.

Surkov V.S., Korobeinikov V.P., Krylov S.V., Grishin M.P., Kraevsky B.G., Larichev A.I., 1996. Geodynamic and Depositional Conditions of Riphean Petroleum Complex Formation on the Western Margin of the Siberian Paleocontinent. Russian Geology and Geophysics 37 (8), 154-166 (in Russian) [Сурков В.С., Коробейников В.П., Крылов С.В., Гришин М.П., Краевский Б.Г., Ларичев А.И. Геодинамические и седиментационные условия формирования рифейских нефтегазоносных комплексов на западной 
окраине Сибирского палеоконтинента // Геология и геофизика. 1996. Т. 37. № 8. С. 154-165].

Thompson A.B., 1982. Dehydration Melting of Pelitic Rocks and the Generation of $\mathrm{H}_{2} \mathrm{O}$-Undersaturated Granitic Liquids. American Journal of Science 282, 1567-1595. https://doi.org/10.2475/ajs.282.10.1567.

Vernikovskaya A.E., Vernikovsky V.A., Matushkin N.Yu., Polyansky O.P., Travin A.V., 2009. Thermochronological Models for the Evolution of A-Type Leucogranites in the Neoproterozoic Collisional Orogen of the Yenisei Ridge. Russian Geology and Geophysics 50 (5), 438-452. https:// doi.org/10.1016/j.rgg.2009.04.002.
Vernikovsky V.A., Vernikovskaya A.E., Kotov A.B., Sal'nikova E.B., Kovach V.P., 2003. Neoproterozoic Accretionary and Collisional Events on the Western Margin of the Siberian Craton: New Geological and Geochronological Evidence from the Yenisey Ridge. Tectonophysics 375 (1-4), 147-168. https://doi.org/10.1016/S0040-1951(03)00337-8.

Vernikovsky V.A., Vernikovskaya A.E., Matushkin N.Y., Polyansky O.P., Laevsky Y.M., Voronin K.V., 2011. A Tectonothermal Model for the Formation of an Orogen at the Postcollisional Stage (by the Example of the Yenisei Ridge, Eastern Siberia). Russian Geology and Geophysics 52 (1), 24-39. https://doi.org/10.1016/j.rgg.2010.12.003. 